\title{
A physico-chemical model to study the ion density distribution in the inner coma of comet $\mathrm{C} / 2016 \mathrm{R} 2$ (Pan-STARRS)
}

\author{
Susarla Raghuram, ${ }^{1 \star}$ Anil Bhardwaj, ${ }^{1}$ Damien Hutsemékers, ${ }^{2}$ Cyrielle Opitom,${ }^{3}$ \\ Jean Manfroid, ${ }^{2}$ and Emmanuel Jehin ${ }^{2}$ \\ ${ }^{1}$ Physical Research Laboratory, Ahmedabad, 380009, India. \\ ${ }^{2}$ STAR Institute - University of Liège, Allée du 6 Août 19c, B-4000 Liège, Belgium. \\ ${ }^{3}$ ESO (European Southern Observatory) - Alonso de Cordova 3107, Vitacura, Santiago Chile.
}

Accepted 2020 December 4. Received 2020 December 4; in original form 2020 August 23

\begin{abstract}
The recent observations show that comet C/2016 R2 (Pan-Starrs) has a unique and peculiar composition when compared with several other comets observed at 2.8 au heliocentric distance. Assuming solar resonance fluorescence is the only excitation source, the observed ionic emission intensity ratios are used to constrain the corresponding neutral abundances in this comet. We developed a physico-chemical model to study the ion density distribution in the inner coma of this comet by accounting for photon and electron impact ionization of neutrals, charge exchange and proton transfer reactions between ions and neutrals, and electron-ion thermal recombination reactions. Our calculations show that $\mathrm{CO}_{2}^{+}$and $\mathrm{CO}^{+}$are the major ions in the inner coma, and close to the surface of nucleus $\mathrm{CH}_{3} \mathrm{OH}^{+}, \mathrm{CH}_{3} \mathrm{OH}_{2}^{+}$and $\mathrm{O}_{2}^{+}$are also important ions. By considering various excitation sources, we also studied the emission mechanisms of different excited states of $\mathrm{CO}^{+}, \mathrm{CO}_{2}^{+}, \mathrm{N}_{2}^{+}$, and $\mathrm{H}_{2} \mathrm{O}^{+}$. We found that the photon and electron impact ionization and excitation of corresponding neutrals significantly contribute to the observed ionic emissions for radial distances smaller than $300 \mathrm{~km}$ and at larger distances, solar resonance fluorescence is the major excitation source. Our modelled ion emission intensity ratios are consistent with the ground-based observations. Based on the modelled emission processes, we suggest that the observed ion emission intensity ratios can be used to derive the neutral composition in the cometary coma only when the ion densities are significantly controlled by photon and photoelectron impact ionization of neutrals rather than by the ion-neutral chemistry.
\end{abstract}

Key words: molecular processes - techniques: spectroscopic - methods: analytical - comets: individual: C/2016 R2 - ultraviolet: planetary systems

\section{INTRODUCTION}

Cometary nuclei are formed due to the agglomeration of different icy grains and dust particles in the outer reaches of the Solar nebula. As the comet approaches the Sun, sublimation of these ices causes a giant gaseous transient atmosphere around the nucleus, which is called a cometary coma. At a given heliocentric distance, sublimation rate of the nucleus is the key deciding factor that determines the dynamical activity of the cometary coma. Most of the observations have shown that during the peak activity of a comet, water is the most dominant component of a cometary coma, whereas at

* E-mail: raghuramsusarla@gmail.com larger heliocentric distances $\mathrm{CO}$ and $\mathrm{CO}_{2}$ are the dominant species. The interaction of solar radiation with cometary species drives a chain of chemical reactions in the inner coma and also leads to various spectroscopic emissions. Remote observation of different spectroscopic emissions from neutrals and ions is a potential tool to study the global composition of comets and the dynamical activity of cometary plasma (Feldman et al. 2004; Bockelée-Morvan et al. 2004). For an active comet, like $1 \mathrm{P} /$ Halley, the solar wind starts to interact with cometary neutrals and ionic species more than a million kilometres away from the nucleus which leads to complex structures in the cometary plasma and magnetic fields (Ip 2004). Depending on the cometary activity and solar wind conditions, various dynamical plasma boundaries, such as bow shock, the cometopause, the collisionopause, 
and the diamagnetic cavity, manifest in the cometary coma. A detailed description of these boundaries is provided in a tutorial by Cravens (1989).

The study of cometary plasma composition has been subjected to a great interest after the ion mass spectrometer onboard Giotto spacecraft detected many peaks in the mass range 12 and 120 amu (Balsiger et al. 1986; Krankowsky et al. 1986; Mitchell et al. 1987; Altwegg et al. 1993). By developing photochemical models, numerous studies focused on comet $1 \mathrm{P} /$ Halley explained the observed ion distribution in a water-dominated coma. (Allen et al. 1987; Wegmann et al. 1987; Schmidt et al. 1988; Cravens 1989; Ip et al. 1990; Gan \& Cravens 1990; Bhardwaj et al. 1990, 1996; Bhardwaj 1999; Haider et al. 1993; Häberli et al. 1995; Haider \& Bhardwaj 1997, 2005; Rubin et al. 2009; Cordiner \& Charnley 2014). By making two years of observations, the recent Rosetta space mission on comet $67 \mathrm{P} / \mathrm{Churyumov}-$ Gerasimenko has revolutionized our understanding of the activity of the cometary coma. During the Rosetta observation period, continuous measurements around the nucleus were helpful to study the evolution of ion and neutral distribution and also the driving photochemical processes in the coma. Several modelling works on this comet have shown that ion composition in the coma varies based on the sublimation rate of the nucleus (Vigren \& Galand 2013; Fuselier et al. 2015, 2016; Galand et al. 2016; Vigren et al. 2017; Heritier et al. 2017, 2018; Beth et al. 2019). All these studies show that solar photons are the primary energy source that determine the ion composition in the inner coma. Solar extreme ultraviolet photons having an energy more than $12 \mathrm{eV}$ ionize $\mathrm{H}_{2} \mathrm{O}$ and produce $\mathrm{H}_{2} \mathrm{O}^{+}$, and the collisions among these species quickly lead to the formation of $\mathrm{H}_{3} \mathrm{O}^{+}$. The sublimated parent species such as $\mathrm{CH}_{3} \mathrm{OH}, \mathrm{NH}_{3}, \mathrm{HCN}, \mathrm{HCOOH}$, $\mathrm{CH}_{3} \mathrm{CHO}$, have high proton affinities compared to that of $\mathrm{H}_{2} \mathrm{O}$, causing the loss of $\mathrm{H}_{3} \mathrm{O}^{+}$in the inner coma. Haider \& Bhardwaj (2005) developed a comprehensive chemical network to study the ion distribution in comet $1 \mathrm{P} /$ Halley. Their calculations show that $\mathrm{NH}_{4}^{+}$is the most dominant ion in the inner coma followed by $\mathrm{H}_{3} \mathrm{O}^{+}$and $\mathrm{CH}_{3} \mathrm{OH}_{2}^{+}$ions. Similarly, the model calculations of Heritier et al. (2017) on comet $67 \mathrm{P} /$ Churyumov-Gerasimenko showed that $\mathrm{NH}_{4}^{+}, \mathrm{CH}_{3} \mathrm{OH}_{2}^{+}$, $\mathrm{H}_{3} \mathrm{O}^{+}, \mathrm{H}_{3} \mathrm{~S}^{+}, \mathrm{HCNH}^{+}$are the important ions in the inner coma. They also showed that the densities of these ions vary with the relative mixing ratios of corresponding proton affinity species coming from the nucleus. Even if the mixing ratios of parent species, which have high proton affinity, are very low $(<2 \%)$, they can play a significant role in modifying the ionospheric composition of the inner coma. Hence, the ion distribution in the cometary coma essentially depends on the neutral composition and photochemical reactions.

The main volatile constituent of the inner coma, $\mathrm{H}_{2} \mathrm{O}$, cannot be detected in the visible due to the lack of electronic transition, which is also the case for $\mathrm{CO}_{2}$ and $\mathrm{N}_{2}$. Several ground based observatories studied the composition of cometary plasma by making spectroscopic observation of different ions. The observed emission intensities of these ions were used to constrain their respective parent species abundances in the coma. $\mathrm{H}_{2} \mathrm{O}^{+}$has been observed in various comets from ground-based observatories (Delsemme \& Combi 1979; Disanti et al. 1990; Häberli et al. 1997; Wegmann et al. 1999). Spectroscopic emissions from $\mathrm{CO}^{+}$have been used to study the dynamics of the plasma in cometary ion tails (Ip 2004; Arpigny 1964; Krishna Swamy 1979; Swamy 1986; Combi \& Delsemme 1980; Larson 1980; Cochran \& Cochran 1991; Cochran et al. 2000). So far a few detections of $\mathrm{N}_{2}^{+}$emissions on comets from ground based observations are reported (Wyckoff \& Theobald 1989; Lutz et al. 1993; Korsun et al. 2008, 2014). But the presence of $\mathrm{N}_{2}$ was more conclusive in comet $67 \mathrm{P} / \mathrm{Churyumov-}$ Gerasimenko from Rosetta in situ measurements (Rubin et al. 2015). As discussed before, besides the composition of parent species, the collisional chemistry can significantly change the ion composition in the inner coma. Hence, the knowledge of formation and loss processes of different ions is essential to constrain their corresponding neutral abundances based on the observed ionic emission intensities.

Several recent observations of comet C/2016 R2 (PanStarrs) - hereafter C/2016 R2 - have shown that the cometary coma is predominantly composed of $\mathrm{CO}$ and remarkably depleted in water, when it was at 2.75 au away from the Sun (Biver et al. 2018; Cochran \& McKay 2018; Wierzchos \& Womack 2018; Opitom et al. 2019; McKay et al. 2019; Venkataramani et al. 2020). Several multiwavelength observations of this comet have shown that it has substantially low $\mathrm{H}_{2} \mathrm{O}$ production rate, which is contrary to many cometary observations made at this heliocentric distance (McKay et al. 2019; Biver et al. 2018). Cochran \& McKay (2018) were the first to report the strong emission features of $\mathrm{CO}^{+}$comet tail bands $\left(\mathrm{A}^{2} \Pi \rightarrow \mathrm{X}^{2} \Sigma\right)$ and $\mathrm{N}_{2}^{+}$first negative bands $\left(\mathrm{B}^{2} \Sigma^{+} \rightarrow \mathrm{X}^{2} \Sigma\right)$ in comet $\mathrm{C} / 2016$ R2, followed by Biver et al. (2018) and Opitom et al. (2019). Besides these emissions, Opitom et al. (2019) also observed $\mathrm{CO}_{2}^{+}$Fox-Duffendack-Barker band system $\left(\widetilde{A}^{2} \Pi \rightarrow\right.$ $\left.\widetilde{X}^{2} \Pi\right)$ in their high resolution optical spectra of this comet. Venkataramani et al. (2020) reported a tentative detection of $\mathrm{H}_{2} \mathrm{O}^{+}\left(\widetilde{A}^{2} A_{1} \rightarrow \widetilde{X}^{2} B_{1}\right)(0-8-0)$ emission in their low resolution observed spectra. But they also claim that the detection is not conclusive due to the strong blend of $\mathrm{CO}^{+}$ doublet emission. However, it should be noted that these $\mathrm{H}_{2} \mathrm{O}^{+}$emissions are not seen in other high resolution optical observations. Assuming that solar resonance florescence is the only excitation source, the measured ionic emission intensity ratios are used to constrain their respective neutral composition in the coma. As discussed before, besides the neutral composition, the ion density in the coma is strongly controlled by ion-neutral chemical reactions. In this case, the conversion of observed ion emission intensity ratios into corresponding neutral density ratios is not straightforward.

In the light of recent observations of comet C/2016 R2 (Opitom et al. 2019), we aim to explore the photochemistry of CO-dominated and water-depleted comet and also the emission mechanisms of different ions. We developed a physico-chemical model for comet $\mathrm{C} / 2016 \mathrm{R} 2$ to study the ion density distribution in the inner coma by incorporating different excitation sources and various chemical reactions. Using our model, we also studied various photochemical processes of different ionic emissions in this comet, which were observed by various ground based observatories. We describe the model inputs such as the neutral composition of the coma, the atomic and molecular parameters, the chemical network of ion-neutral chemistry, and the photochemical reactions of excited states of ions in Section 3. In this section, we also explain the calculation of radial density profiles of 
different ions and the emission intensity profiles of the excited states of $\mathrm{CO}_{2}^{+}, \mathrm{CO}^{+}, \mathrm{N}_{2}^{+}$, and $\mathrm{H}_{2} \mathrm{O}^{+}$as a function of the nucleocentric projected distance. The modelled production and loss mechanisms of different ions and their density distribution, volume emissions rates of excited states, and intensity ratios of different ionic emissions are presented in Section 4. The inferences of the model calculations are discussed in Section 5. We summarize the current work and draw the conclusions in Section 6.

\section{OBSERVATIONS}

Observations of comet C/ 2016 R2 were carried out on 2018 February 11-16 with the Ultraviolet-Visual Echelle Spectrograph (UVES) mounted on the $8.2 \mathrm{~m}$ UT2 telescope of the European Southern Observatory Very Large Telescope. The slit width of $0.44^{\prime \prime}$ gives a resolving power $\mathrm{R}$ $\simeq 80000$. Full account of the observations and data reductions is given in Opitom et al. (2019). Opitom et al. (2019) used the measured fluxes for $\mathrm{N}_{2}^{+}\left(\mathrm{B}^{2} \Sigma^{+} \rightarrow \mathrm{X}^{2} \Sigma\right)(0-0), \mathrm{CO}_{2}^{+}$ $\left(\widetilde{A}^{2} \Pi \rightarrow \widetilde{X}^{2} \Pi\right)(0-0)$, and $\mathrm{CO}^{+}\left(\mathrm{A}^{2} \Pi \rightarrow \mathrm{X}^{2} \Sigma\right)(2-0)$ band emissions, at respective wavelengths 391,351 and $425 \mathrm{~nm}$, to derive the ion density ratios in the coma. They also considered $\mathrm{H}_{2} \mathrm{O}^{+}\left(\widetilde{A}^{2} A_{1} \rightarrow \widetilde{X}^{2} B_{1}\right)$ (0-8-0) band emission to constrain the upper limit of the $\mathrm{H}_{2} \mathrm{O}^{+}$abundance in the coma. Assuming solar resonance fluorescence is the only excitation mechanism, the observed emission flux ratios are used to derive ionic abundance ratios. They derived ionic ratios of $\mathrm{N}_{2}^{+} / \mathrm{CO}^{+}, \mathrm{CO}_{2}^{+} / \mathrm{CO}^{+}$, and $\mathrm{H}_{2} \mathrm{O}^{+} / \mathrm{CO}^{+}$in the cometary coma of $0.06 \pm 0.01,1.1 \pm 0.3$, and $<0.4$, respectively. These ratios were computed using intensities averaged over the full slit length. For the UVES blue arm spectra where the ionic emissions of interest are located, the slit extends over $\sim 1.5$ $\times 10^{4} \mathrm{~km}$ at the comet distance. Surface brightnesses were also measured on the two-dimensional spectra, cutting the slit in chunks as done in Raghuram et al. (2020) for the [OI] spectral lines (which are located in the red arm spectra). For the blue settings, the spectra were rebinned along the spatial dimension so that the final pixel size projected onto the comet corresponds to $0.125^{\prime \prime}$ (about $220 \mathrm{~km}$ ). Seven spatial chunks were defined, the central one ranging from -3 to +3 pixels, and the other ones corresponding to the pixel ranges $[-24,-18],[-17,-11],[-10,-4],[4,10],[11,17]$, and $[18,24]$. The intensity ratios are given in Table 1 as a function of the projected nucleocentric distance (radius). The radius is given as the central value in each subslit plus or minus the range divided by two. The measurements done on each side of the comet in a given range of nucleocentric distances were averaged. The errors are dominated by the uncertainties from the fitting procedure (Opitom et al. 2019). There is no significant variation of the $\mathrm{I}\left(\mathrm{N}_{2}^{+}\right) / \mathrm{I}\left(\mathrm{CO}^{+}\right)$intensity ratio with the nucleocentric distance, while the $\mathrm{I}\left(\mathrm{CO}_{2}^{+}\right) / \mathrm{I}\left(\mathrm{CO}^{+}\right)$ratio apparently decreases by a factor 2 at $\sim 5000 \mathrm{~km}$ from the nucleus.

\section{MODEL INPUTS AND CALCULATIONS}

The detailed description of model calculations is provided in our earlier work (Bhardwaj \& Raghuram 2012; Raghuram \& Bhardwaj 2013, 2014; Decock et al. 2015; Raghuram et al. 2016, 2020). The model inputs such as the heliocentric and geocentric distances, the nucleus sublimation rate, and the
Table 1. The measured ionic emission intensity ratios on comet $\mathrm{C} / 2016 \mathrm{R} 2$ as a function of the projected distance when it was at 2.75 au heliocentric distance

\begin{tabular}{lcc}
\hline $\begin{array}{l}\text { Radius } \\
\left(10^{3} \mathrm{~km}\right)\end{array}$ & $\mathrm{I}\left(\mathrm{N}_{2}^{+}\right) / \mathrm{I}\left(\mathrm{CO}^{+}\right)$ & $\mathrm{I}\left(\mathrm{CO}_{2}^{+}\right) / \mathrm{I}\left(\mathrm{CO}^{+}\right)$ \\
\hline $0.3875 \pm 0.3875$ & $1.14 \pm 0.2$ & $0.17 \pm 0.04$ \\
$1.550 \pm 0.775$ & $1.18 \pm 0.2$ & $0.17 \pm 0.04$ \\
$3.100 \pm 0.775$ & $1.19 \pm 0.2$ & $0.14 \pm 0.04$ \\
$4.650 \pm 0.775$ & $1.24 \pm 0.2$ & $0.08 \pm 0.04$ \\
\hline
\end{tabular}

gaseous composition of $\mathrm{C} / 2016 \mathrm{R} 2$ coma are the same as described in our recent work (Raghuram et al. 2020). Here we briefly describe the neutral distribution of coma, the atomic and molecular parameters, and the chemical network used for calculating the ion density profiles and emission intensity profiles of various ions.

\subsection{Neutral distribution}

We consider eight neutral species viz., $\mathrm{H}_{2} \mathrm{O}, \mathrm{CO}, \mathrm{CO}_{2}, \mathrm{~N}_{2}$, $\mathrm{CH}_{3} \mathrm{OH}, \mathrm{CH}_{4}, \mathrm{NH}_{3}$, and $\mathrm{O}_{2}$ as the primary composition of the cometary coma. Abundances of these species are taken from the various ground-based observations which were made when the comet was at a heliocentric distance of $2.8 \mathrm{au}$. At this heliocentric distance, Biver et al. (2018) observed that $\mathrm{CO}$ is the most dominant species in the coma with a gas production rate of $1.1 \times 10^{29} \mathrm{~s}^{-1}$. We have taken the relative abundances of other neutral species viz., $\mathrm{H}_{2} \mathrm{O}$, $\mathrm{CO}_{2}, \mathrm{~N}_{2}, \mathrm{CH}_{3} \mathrm{OH}$, and $\mathrm{CH}_{4}$ as $0.3 \%, 18 \%, 7 \%, 1.1 \%$, and $0.6 \%$, respectively, with respect to $\mathrm{CO}$ production rate, from the observations of Biver et al. (2018) and McKay et al. (2019).

In a water-dominated comet, $\mathrm{NH}_{3}$ can play an important role in modifying the ion-density distribution in the inner coma due to high proton affinity. In comet $1 \mathrm{P} /$ Halley, with a $1.5 \%$ mixing ratio in the coma (relative to water production rate), Haider \& Bhardwaj (2005) showed that $\mathrm{NH}_{3}$ quickly reacts with water ion and produces $\mathrm{NH}_{4}^{+}$as the dominant ion in the inner coma. Similarly, the modelling works of Vigren \& Galand (2013) and Heritier et al. (2017) in comet $67 \mathrm{P} /$ Churyumov-Gerasimenko also showed that $\mathrm{NH}_{3}$ and $\mathrm{CH}_{3} \mathrm{OH}$ react with $\mathrm{H}_{2} \mathrm{O}^{+}$and produce protonated ions. To explore the role of $\mathrm{NH}_{3}$ and $\mathrm{CH}_{3} \mathrm{OH}$ in the ion-neutral chemistry of CO-dominated coma, we incorporated the abundance of these species based on the observations of McKay et al. (2019) and Biver et al. (2018). We considered $0.01 \%$ of $\mathrm{NH}_{3}$ relative to $\mathrm{CO}$ production rate in the model based on the derived upper limit by McKay et al. (2019).

The detection of $\mathrm{O}_{2}$ in comets $67 \mathrm{P} /$ ChuryumovGerasimenko and $1 \mathrm{P} /$ Halley suggest that this species might be a common and abundant primary species (Bieler et al. 2015; Rubin et al. 2015). To explore the role of this neutral species in determining the $\mathrm{O}_{2}^{+}$ion density in the $\mathrm{C} / 2016$ $\mathrm{R} 2$ coma, we assumed $1 \%$ of $\mathrm{O}_{2}$ abundance with respect to $\mathrm{CO}$ production rate (Raghuram et al. 2020). However, we show that the inclusion of this species in the model with a large abundance does not influence the modelled ion-density profiles.

Other species such as $\mathrm{HCN}, \mathrm{C}_{2} \mathrm{H}_{6}$ and $\mathrm{H}_{2} \mathrm{CO}$ are also detected in this comet. However, their production rates are 
Table 2. Summary of the baseline input parameters used in the model

\begin{tabular}{ll}
\hline \hline CO production rate & $\mathrm{QCO}_{\mathrm{C}}=1.1 \times 10^{29} \mathrm{~s}^{-1}$ \\
Neutral composition & $\dagger$ \\
& $\mathrm{H}_{2} \mathrm{O}(0.3 \%), \mathrm{CO}_{2}(18 \%)$ \\
& $\mathrm{N}_{2}(7 \%), \mathrm{CH}_{3} \mathrm{OH}(1.1 \%)$, \\
& $\mathrm{CH}_{4}(0.6 \%), \mathrm{NH}_{3}(0.01 \%)$, \\
& and $\mathrm{O}_{2}(1 \%)$ \\
Heliocentric distance & $2.8 \mathrm{au}$ \\
Geocentric distance & $2.44 \mathrm{au}$ \\
Neutral gas expansion velocity & $\mathrm{Ip}(1983)$
\end{tabular}

†The values in the brackets are the abundances of the species relative to the $\mathrm{CO}$ production rate

smaller by more than three orders of magnitude compared to that of CO (McKay et al. 2019). Due to their low relative abundances in comet $\mathrm{C} / 2016 \mathrm{R} 2$, they do not play any significant role in the ion-neutral chemistry. Hence, we did not account for these species in our model.

Density profiles for the primary neutral species are determined using the Haser's distribution formula and the model calculations are done under spherical symmetric assumption (Haser 1957). The neutral gas expansion velocity profile is taken from the hydro-dynamical calculations of Ip (1983) for the CO-dominated coma. We assumed that the electron temperature profile is the same as the thermal temperature profile derived by Ip (1983) and the impact of this assumption on the modelled emission intensity ratios will be discussed later. Our baseline model input parameters are tabulated in Table 2 .

\subsection{Atomic and molecular parameters}

\subsubsection{Cross sections}

The photon absorption and ionization cross sections of various neutrals are taken from the compilation of Huebner et al. (1992), which are accessible from a web link (https://phidrates.space.swri.edu). Electron impact ionization and excitation cross sections of neutral species are compiled from different works (Itikawa \& Mason 2005; Itikawa 2002; Itikawa 2009; Shirai et al. 2001; Tabata et al. 2006; Liu \& Victor 1994; Srivastava et al. 1996; Straub et al. 1997; Rao \& Srivastava 1992).

The branching ratios for the photoionization of $\mathrm{H}_{2} \mathrm{O}$, $\mathrm{N}_{2}, \mathrm{CO}_{2}$, and $\mathrm{CO}$, producing the respective excited $\mathrm{H}_{2} \mathrm{O}^{+}\left(\widetilde{A}^{2} \mathrm{~A}_{1}\right), \mathrm{N}_{2}^{+}\left(\mathrm{B}^{2} \Sigma_{u}^{+}\right), \mathrm{CO}_{2}^{+}\left(\widetilde{A}^{2} \Pi_{u, 3 / 2}\right)$ and $\mathrm{CO}^{+}\left(\mathrm{A}^{2} \Pi\right)$ are taken from Avakyan et al. (1998). Based on the measured photon branching ratio, we assumed that about $50 \%$ of $\mathrm{H}_{2} \mathrm{O}^{+}$is produced in the $\widetilde{A}^{2} \mathrm{~A}_{1}$ excited state for electron impact ionization. Later we discuss the impact of this assumption on the modelled intensity profile. The electron impact cross sections for $\mathrm{CO}_{2}^{+}, \mathrm{CO}^{+}$, and $\mathrm{N}_{2}^{+}$producing in the $\widetilde{A}^{2} \Pi_{u, 3 / 2}, \mathrm{~A}^{2} \Pi$, and $\mathrm{B}^{2} \Sigma_{u}^{+}$excited states, respectively, are taken from Shirai et al. (2001) and Tabata et al. (2006). We obtained Frank-Condon factors and branching ratios for the observed electronic transition of $\mathrm{CO}^{+}(2-0), \mathrm{CO}_{2}^{+}(0-$ $0), \mathrm{N}_{2}^{+}(0-0)$ and $\mathrm{H}_{2} \mathrm{O}^{+}(8-0)$ from different theoretical works (McCallum \& Nicholls 1971; Kim 1999; Judge \& Lee 1973; Arqueros \& Campos 1982; Jain \& Sahni 1966; Lutz et al. 1993; Lofthus \& Krupenie 1977; Lutz 1987). We multiplied these branching ratios and Frank-Condon factors with cor- responding volume emission rates, which are calculated for photon and electron impact excitation of neutral, to calculate the corresponding band emission intensities of the ions.

The solar resonance fluorescence efficiencies (g-factors) of $\mathrm{H}_{2} \mathrm{O}^{+}, \mathrm{CO}^{+}, \mathrm{N}_{2}^{+}$, and $\mathrm{CO}_{2}^{+}$for corresponding ionic band emissions are taken as $4.2 \times 10^{-3}\left(\mathrm{~g}_{\mathrm{H}_{2} \mathrm{O}^{+}}\right), 3.55 \times 10^{-3}$ $\left(\mathrm{g}_{\mathrm{CO}}+\right), 7 \times 10^{-2}\left(\mathrm{~g}_{N_{2}^{+}}\right)$, and $4.96 \times 10^{-4}\left(\mathrm{~g}_{\mathrm{CO}_{2}^{+}}\right)$photons $\mathrm{s}^{-1} \mathrm{~mol}^{-1}$ from Lutz et al. (1993), Magnani \& A'Hearn (1986), Lutz et al. (1993), and Kim (1999), respectively. These excitation rate factors are scaled as a function of inverse square of heliocentric distance of the comet.

\subsubsection{Chemical network}

We considered various ionization processes of neutrals by photons and photoelectrons which produce different ions in the coma. Various chemical reactions such as charge exchange, proton transfer, and thermal recombination are compiled from the literature. Most of these reactions are taken from the UMIST Rate2012 data base (McElroy et al. 2013, http://udfa.ajmarkwick.net) and their accuracy is within $25 \%$. The chemical network used to model ion density distribution in C/2016 R2 is presented in Tables A1 and A2 of Appendix A. We calculated various photon and electron impact initiated photochemical reaction rates that produce the excited states of $\mathrm{CO}_{2}^{+}, \mathrm{CO}^{+}, \mathrm{H}_{2} \mathrm{O}^{+}$, and $\mathrm{N}_{2}^{+}$ions, which are tabulated in Table B1 of Appendix B.

\subsection{Calculations}

\subsubsection{Ion density profiles}

The degradation of the solar radiation and calculation of suprathermal electron flux in the cometary coma was described in our earlier work (Bhardwaj et al. 1990, 1996; Bhardwaj \& Raghuram 2012; Raghuram et al. 2020; Raghuram \& Bhardwaj 2020, 2013; Bhardwaj 1999). Using the modelled solar photon and the suprathermal electron flux profiles and corresponding cross sections, we determined the volume production rates of different ions for photoionization and electron impact ionization of neutrals. Besides the photon and electron impact ionization, various chemical reactions are also accounted for to determine radial ion density profiles. Based on the observed neutral composition, we modelled density distribution of thirteen ions viz., $\mathrm{H}_{2} \mathrm{O}^{+}, \mathrm{H}_{3} \mathrm{O}^{+}, \mathrm{CO}_{2}^{+}, \mathrm{CO}^{+}, \mathrm{O}_{2}^{+}, \mathrm{N}_{2}^{+}, \mathrm{NH}_{3}^{+}, \mathrm{CH}_{3} \mathrm{OH}^{+}$, $\mathrm{CH}_{4}^{+}, \mathrm{CH}_{3} \mathrm{OH}_{2}^{+}, \mathrm{NH}_{4}^{+}, \mathrm{C}^{+}$, and $\mathrm{O}^{+}$in the cometary coma. We solved the following time-dependent spherical continuity equation for all the ions simultaneously to determine the steady state ion density profiles :

$\frac{\partial n_{i}}{\partial t}+\frac{1}{r^{2}} \frac{\partial\left(n_{i} v_{i} r^{2}\right)}{\partial r}=P_{i}-n_{i} L_{i}$

where $n_{i}, P_{i}$, and $\mathrm{L}_{i}$ are the ion density, total production rate, and loss frequency of the $i t h$ ion at radial distance $r$. $v_{i}$ is the mean ion outflow velocity which is assumed to be same as neutral velocity.

\subsubsection{Emission intensities of $\mathrm{CO}_{2}^{+}, \mathrm{CO}^{+}, \mathrm{N}_{2}^{+}$, and $\mathrm{H}_{2} \mathrm{O}^{+}$}

We accounted for photoionization, electron impact ionization of neutrals, and solar resonance fluorescence excitation mechanisms to calculate the volume emission rates $(V E R)$ 
of excited states of ions. To account for the resonance fluorescence excitation mechanism, the modelled ion density profiles are multiplied with corresponding g-factors. The total volume emission rates of $\mathrm{CO}_{2}^{+}\left(\widetilde{A}^{2} \Pi_{u, 3 / 2}\right), \mathrm{N}_{2}^{+}\left(\mathrm{B}^{2} \Sigma_{u}^{+}\right)$, $\mathrm{H}_{2} \mathrm{O}^{+}\left(\widetilde{A}^{2} \mathrm{~A}_{1}\right)$, and $\mathrm{CO}^{+}\left(\mathrm{A}^{2} \Pi\right)$ are given by

$$
\begin{aligned}
\operatorname{VER}_{\left(\mathrm{CO}_{2}^{+*}\right)} & =I_{f 1}\left[\mathrm{CO}_{2}\right]+g_{\mathrm{CO}_{2}^{+}}\left[\mathrm{CO}_{2}^{+}\right] \\
\operatorname{VER}_{\left(\mathrm{N}_{2}^{+*}\right)} & =I_{f 2}\left[\mathrm{~N}_{2}\right]+g_{N_{2}^{+}}\left[\mathrm{N}_{2}^{+}\right] \\
V E R_{\left(\mathrm{H}_{2} \mathrm{O}^{+*}\right)} & =I_{f 3}\left[\mathrm{H}_{2} \mathrm{O}\right]+g_{\mathrm{H}_{2} \mathrm{O}^{+}}\left[\mathrm{H}_{2} \mathrm{O}^{+}\right] \\
V E R_{\left(C \mathrm{O}^{+*}\right)} & =I_{f 4}\left[\mathrm{CO}_{2}\right]+I_{f 5}[\mathrm{CO}]+g_{C O^{+}}\left[\mathrm{CO}^{+}\right]
\end{aligned}
$$

where species in the brackets are corresponding neutral and ion densities. Species in the parenthesis are the excited states of ions. $\mathrm{I}_{f 1}$ to $\mathrm{I}_{f 5}$ are the total ionization and excitation frequencies of the excited states of the ions via photon and electron impact ionization of the respective neutrals. The volume emission rates are integrated along the line of sight and surface brightness profiles are determined as a function of the nucleocentric projected distance. The ion emission intensity ratios are determined from the modelled surface brightness profiles and compared with the observations.

\section{RESULTS}

\subsection{Production and loss mechanisms of $\mathrm{CO}_{2}^{+}$}

The modelled volume production rate and loss frequency profiles of $\mathrm{CO}_{2}^{+}$for different photochemical reactions are presented in the respective top and bottom panels of Figure 1. Photoionization of $\mathrm{CO}_{2}$ and charge exchange between $\mathrm{CO}^{+}$ and $\mathrm{CO}_{2}$ are the important production sources of $\mathrm{CO}_{2}^{+}$in this comet. Electron impact ionization of $\mathrm{CO}_{2}$ and charge exchange of $\mathrm{N}_{2}^{+}$with $\mathrm{CO}_{2}$ contribute little to the total formation of $\mathrm{CO}_{2}^{+}$. The modelled loss processes presented in the lower panel of Figure 1 show that for radial distances smaller than $100 \mathrm{~km}$, the collisions with $\mathrm{H}_{2} \mathrm{O}$ significantly remove $\mathrm{CO}_{2}^{+}$in the coma. Above this distance, thermal recombination is the significant loss source for $\mathrm{CO}_{2}^{+}$.

\subsection{Production and loss mechanisms of $\mathrm{CO}^{+}$}

Figure 2 shows the modelled production rate and loss frequency profiles of $\mathrm{CO}^{+}$for different photochemical processes. As shown in the top panel of this Figure, photoionization of $\mathrm{CO}$ is the major formation channel of $\mathrm{CO}^{+}$in the cometary coma. Close to the surface of the nucleus, electron impact ionization of $\mathrm{CO}$ and the collisions between $\mathrm{C}^{+}$and $\mathrm{CO}_{2}$ are also important production sources of $\mathrm{CO}^{+}$. The formation rates of $\mathrm{CO}^{+}$via dissociative ionization of $\mathrm{CO}_{2}$ by photons and photoelectrons, and other charge exchange reactions are smaller by more than an order of magnitude compared to that of photoionization of CO. The calculated loss frequency profiles in the bottom panel of Figure 2 show that the collisions with $\mathrm{CO}_{2}$ is major loss source of $\mathrm{CO}^{+}$for radial distances smaller than $10^{3} \mathrm{~km}$. Above this distance, thermal recombination is the significant loss source of $\mathrm{CO}^{+}$. Other charge exchange reactions play a minor role in the removal of $\mathrm{CO}^{+}$.
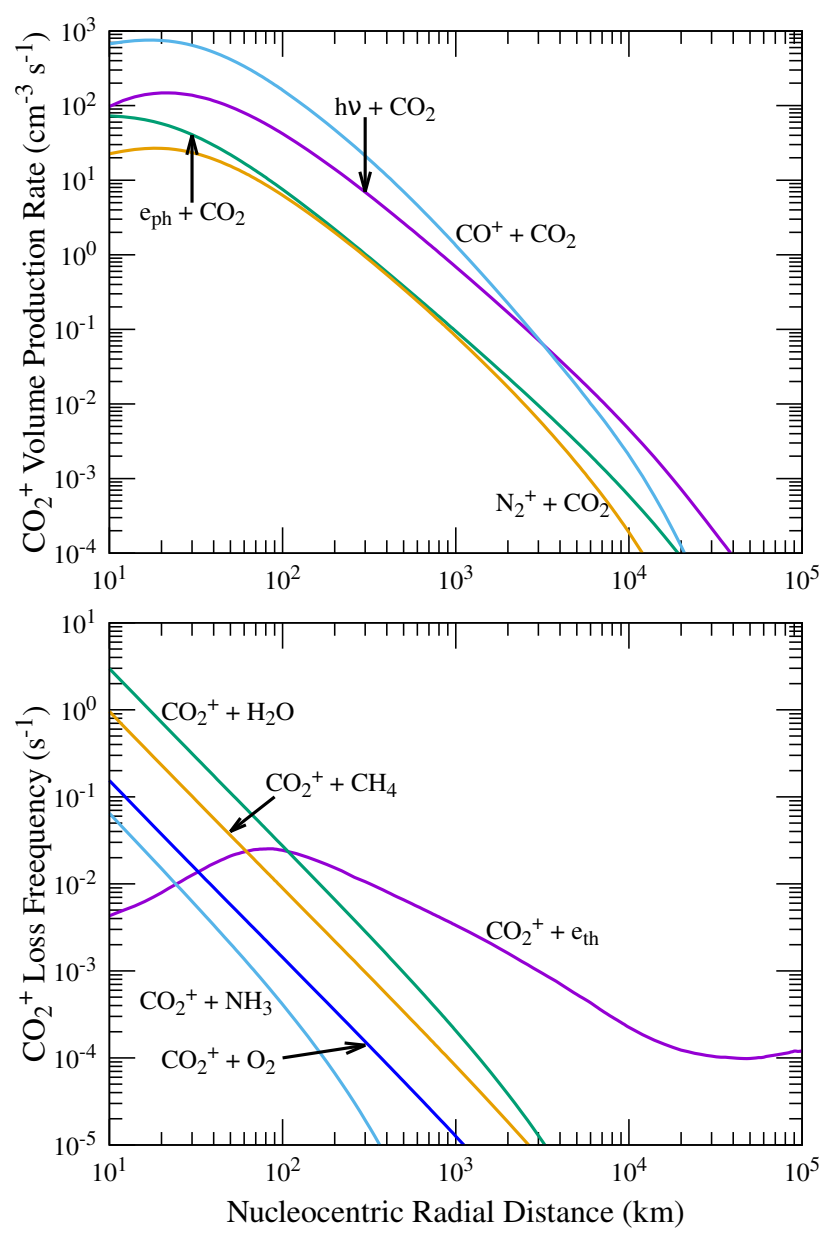

Figure 1. Modelled production rate (top panel) and loss frequency profiles (bottom panel) of $\mathrm{CO}_{2}^{+}$in the coma of comet $\mathrm{C} / 2016 \mathrm{R} 2$. Calculations are done at 2.8 au heliocentric distance using a $\mathrm{CO}$ production rate of $1.1 \times 10^{29} \mathrm{~s}^{-1}$. The relative abundances of other species viz., $\mathrm{H}_{2} \mathrm{O}, \mathrm{CO}_{2}, \mathrm{~N}_{2}, \mathrm{CH}_{3} \mathrm{OH}, \mathrm{CH}_{4}, \mathrm{O}_{2}$, and $\mathrm{NH}_{3}$ are taken as $0.3 \%, 18 \%, 7 \%, 1.1 \%, 0.6 \%, 1 \%$, and $0.01 \%$, respectively, with respect to $\mathrm{CO}$ production rate. $\mathrm{h} \nu, \mathrm{e}_{p h}$, and $\mathrm{e}_{t h}$ represent solar photon, photoelectron, and thermal electron, respectively.

\subsection{Production and loss mechanisms of $\mathrm{H}_{2} \mathrm{O}^{+}$}

Generally in comets, which are $\mathrm{H}_{2} \mathrm{O}$ dominated, the main production source of $\mathrm{H}_{2} \mathrm{O}^{+}$is photoionization and electron impact ionization of $\mathrm{H}_{2} \mathrm{O}$. Our model calculations in the top panel of Figure 3 show that in comet $\mathrm{C} / 2016 \mathrm{R} 2$, charge exchange between $\mathrm{CO}_{2}^{+}$and $\mathrm{H}_{2} \mathrm{O}$ is the major production of source of $\mathrm{H}_{2} \mathrm{O}^{+}$in the inner coma. Close to the surface of the nucleus, charge exchange between $\mathrm{CH}_{3} \mathrm{OH}^{+}$and $\mathrm{H}_{2} \mathrm{O}$ is also another important formation source of $\mathrm{H}_{2} \mathrm{O}^{+}$. It can be noticed in this figure that for radial distances smaller than $1000 \mathrm{~km}$, the formation rate of $\mathrm{H}_{2} \mathrm{O}^{+}$via photoionization of $\mathrm{H}_{2} \mathrm{O}$ is smaller by more than two orders of magnitude compared to the production rate of $\mathrm{H}_{2} \mathrm{O}^{+}$due to charge exchange between $\mathrm{CO}_{2}^{+}$and $\mathrm{H}_{2} \mathrm{O}$. At larger radial distances (about $10^{4} \mathrm{~km}$ ), charge exchange between $\mathrm{O}^{+}$and $\mathrm{H}_{2} \mathrm{O}$ significantly produces $\mathrm{H}_{2} \mathrm{O}^{+}$and several other sources are also involved in the production of this ion. As shown in the bottom panel of Figure 3, the collisions between $\mathrm{H}_{2} \mathrm{O}^{+}$and $\mathrm{CO}$, which lead to the formation of $\mathrm{HCO}^{+}$, is the major 

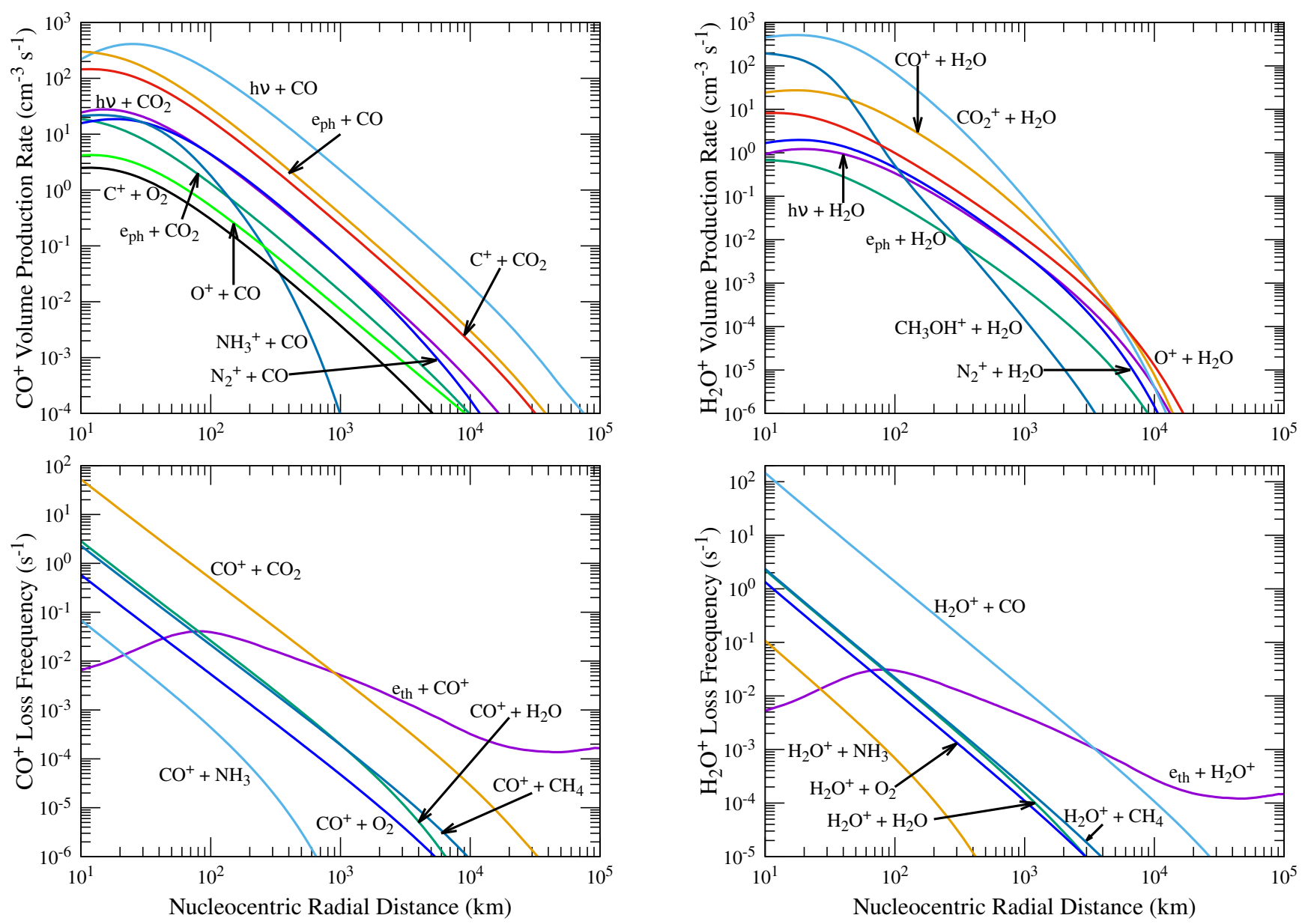

Figure 2. Modelled production rate (top panel) and loss frequency (bottom panel) profiles of $\mathrm{CO}^{+}$in the coma of comet C/2016 R2. Input conditions are the same as explained in Figure $1 . \mathrm{h} \nu, \mathrm{e}_{p h}$, and $\mathrm{e}_{t h}$ represent solar photon, photoelectron, and thermal electron, respectively.

loss source of $\mathrm{H}_{2} \mathrm{O}^{+}$for radial distances below $3000 \mathrm{~km}$ and other collisional loss frequencies are smaller by more than an order of magnitude compared to the former. Above this radial distance thermal recombination is a significant loss source of $\mathrm{H}_{2} \mathrm{O}^{+}$.

\subsection{Production and loss mechanisms of $\mathrm{N}_{2}^{+}$}

The modelled production rate profiles in the top panel of Figure 4 show that $\mathrm{N}_{2}^{+}$is produced in the coma of $\mathrm{C} / 2016$ $\mathrm{R} 2$ via photon and electron impact ionization of $\mathrm{N}_{2}$. Modelled loss profiles in the bottom panel of this Figure show that several collisional mechanisms are involved in the removal of $\mathrm{N}_{2}^{+}$in the inner coma. The charge exchange of $\mathrm{N}_{2}^{+}$ with $\mathrm{CO}$ and $\mathrm{CO}_{2}$ are the significant loss mechanisms for radial distances below $3000 \mathrm{~km}$ and above this radial distance thermal recombination is the major loss source for this ion.

\subsection{Production and loss mechanisms of $\mathrm{CH}_{3} \mathrm{OH}^{+}$}

The modelled production rate and loss frequency profiles, which are presented in the respective top and bottom panels of Figure 5, show that photoionization of $\mathrm{CH}_{3} \mathrm{OH}$ is the

Figure 3. Modelled production rate (top panel) and loss frequency (bottom panel) profiles of $\mathrm{H}_{2} \mathrm{O}^{+}$via various mechanisms in the coma of comet C/2016 R2. Input conditions are the same as explained in Figure $1 . \mathrm{h} \nu, \mathrm{e}_{p h}$, and $\mathrm{e}_{t h}$ represent solar photon, photoelectron, and thermal electron, respectively.

most important formation source of $\mathrm{CH}_{3} \mathrm{OH}^{+}$for radial distances above $300 \mathrm{~km}$. But below this radial distance, the charge exchange between $\mathrm{O}_{2}^{+}$and $\mathrm{CH}_{3} \mathrm{OH}$ is an important source mechanism. As shown in the bottom panel, proton transfer between $\mathrm{CH}_{3} \mathrm{OH}^{+}$and $\mathrm{H}_{2} \mathrm{O}$ removes this ion for radial distances smaller than $50 \mathrm{~km}$, above which thermal recombination takes over as the major loss source.

\subsection{Production and loss mechanisms of $\mathrm{NH}_{3}^{+}$}

Modelled production and loss rate profiles of $\mathrm{NH}_{3}^{+}$for different mechanisms are presented in top and bottom panels of Figure 6, respectively. Collisions of $\mathrm{NH}_{3}$ with $\mathrm{CO}_{2}^{+}, \mathrm{CO}^{+}$, and $\mathrm{O}_{2}^{+}$are the dominant production sources of $\mathrm{NH}_{3}^{+}$for radial distances below $10^{3} \mathrm{~km}$. The formation rate of $\mathrm{NH}_{3}^{+}$due to photoionization of $\mathrm{NH}_{3}$ is smaller by more than a factor of 5 compared to that from the charge exchange between $\mathrm{CO}_{2}^{+}$and $\mathrm{NH}_{3}$. For radial distances below $10^{4} \mathrm{~km}$, collisions with $\mathrm{CO}$ is the most significant loss process of $\mathrm{NH}_{3}^{+}$and at larger radial distances thermal recombination removes this ion in the inner coma of comet C/2016 R2. 

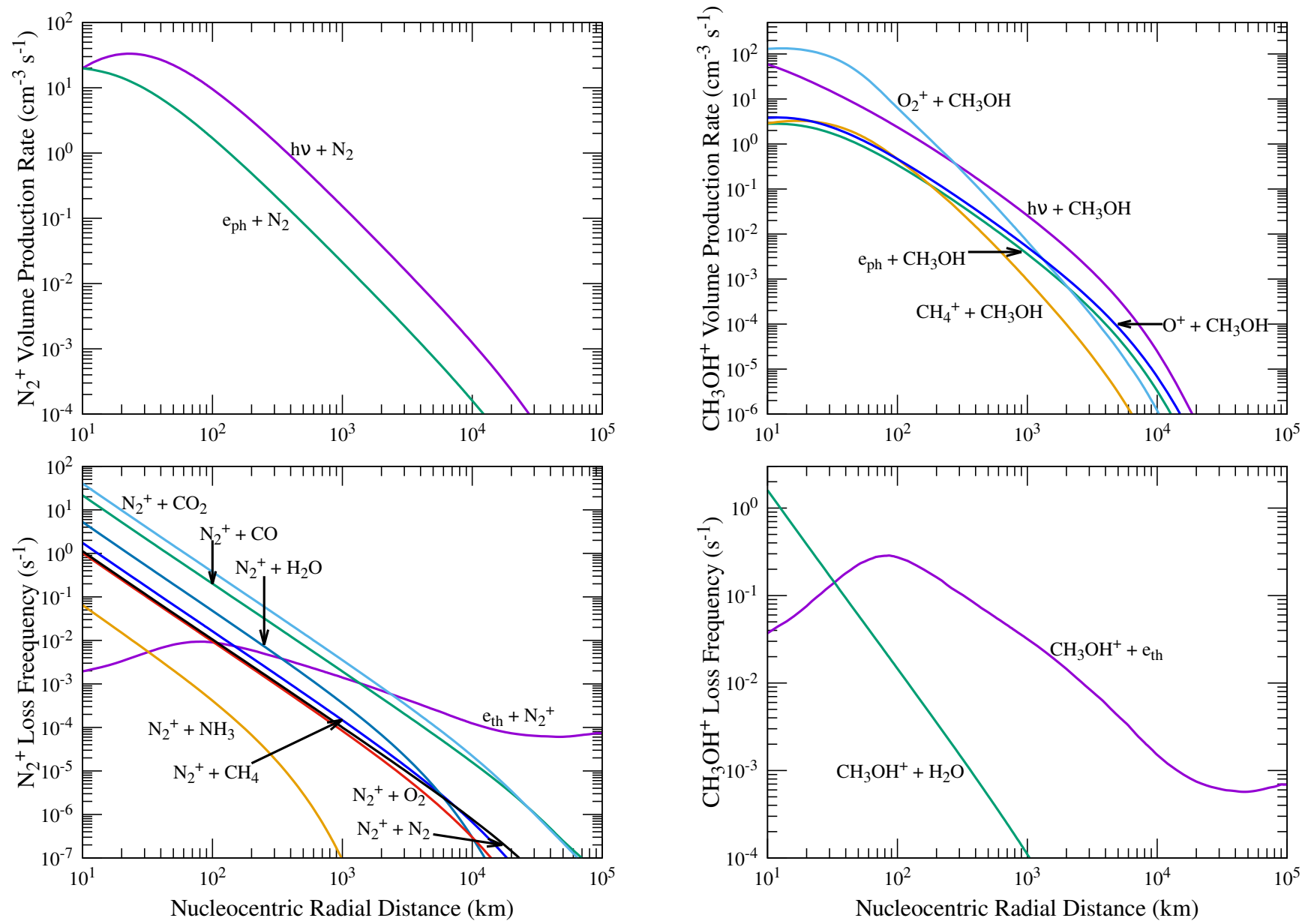

Figure 4. Modelled production rate (top panel) and loss frequency (bottom panel) profile of $\mathrm{N}_{2}^{+}$in the coma of comet C/2016 R2. Input conditions are same as explained in Figure 1. $\mathrm{h} \nu, \mathrm{e}_{p h}$, and $\mathrm{e}_{t h}$ represents solar photon, photoelectron, and thermal electron, respectively.

\subsection{Production and loss mechanisms of $\mathrm{CH}_{4}^{+}$}

The top panel of Figure 7 shows that charge exchange between $\mathrm{CO}_{2}^{+}$and $\mathrm{CH}_{4}$ is the major production source of $\mathrm{CH}_{4}^{+}$ for radial distances below $1000 \mathrm{~km}$ and above this distance photoionization of $\mathrm{CH}_{4}$ and charge exchange between $\mathrm{CO}^{+}$ and $\mathrm{CH}_{4}$ are the most significant sources of this ion. Several collisional mechanisms are incorporated to determine the total chemical loss frequency of $\mathrm{CH}_{4}^{+}$. The modelled loss frequency profiles of $\mathrm{CH}_{4}^{+}$in the bottom panel of Figure 7 show that collisional reaction between $\mathrm{CH}_{4}^{+}$and $\mathrm{CO}$ is the dominant loss mechanism for the radial distances below $10^{4} \mathrm{~km}$ and above this distance thermal recombination is the major loss process for $\mathrm{CH}_{4}^{+}$. Several other collisional processes play negligible role in the removal of $\mathrm{CH}_{4}^{+}$in the inner coma.

\subsection{Production and loss mechanisms of $\mathrm{O}_{2}^{+}$}

The modelled formation and loss profiles of $\mathrm{O}_{2}^{+}$are presented in Figure 8. The calculated production rates profiles in the top panel of this Figure show that collisional reaction between $\mathrm{O}^{+}$and $\mathrm{CO}_{2}$ is the significant production source of $\mathrm{O}_{2}^{+}$in the inner coma rather than photoionization of $\mathrm{O}_{2}$.

Figure 5. Modelled production rate (top panel) and loss frequency profiles (bottom panel) of $\mathrm{CH}_{3} \mathrm{OH}^{+}$in the coma of comet $\mathrm{C} / 2016 \mathrm{R} 2$. Input conditions are same as explained in Figure 1. $\mathrm{h} \nu, \mathrm{e}_{p h}$, and $\mathrm{e}_{t h}$ represent solar photon, photoelectron, and thermal electron, respectively.

Loss frequency profiles presented in the bottom panel of Figure 8 show that collisions with $\mathrm{CH}_{3} \mathrm{OH}$ significantly remove $\mathrm{O}_{2}^{+}$for radial distances below $100 \mathrm{~km}$ and at larger radial distances thermal recombination takes over as the dominant loss mechanism.

\subsection{Production and loss mechanisms of protonated ions $\mathrm{H}_{3} \mathrm{O}^{+}, \mathrm{CH}_{3} \mathrm{OH}_{2}^{+}$, and $\mathrm{NH}_{4}^{+}$}

As shown in the top panel of Figure 9, proton transfer reactions of $\mathrm{H}_{2} \mathrm{O}^{+}$with $\mathrm{H}_{2} \mathrm{O}$ and $\mathrm{CH}_{4}$ ions produce $\mathrm{H}_{3} \mathrm{O}^{+}$with equal production rates in the inner coma. At radial distances larger than $10^{4} \mathrm{~km}$ proton transfer between $\mathrm{H}_{2} \mathrm{O}$ and $\mathrm{CH}_{4}^{+}$ is also an important source of $\mathrm{H}_{3} \mathrm{O}^{+}$. The modelled loss frequency profiles of $\mathrm{H}_{3} \mathrm{O}^{+}$in the bottom panel of Figure 9 show that the proton transfer reaction between $\mathrm{H}_{3} \mathrm{O}^{+}$and $\mathrm{CH}_{3} \mathrm{OH}$ is the most significant loss source of $\mathrm{H}_{3} \mathrm{O}^{+}$for radial distances smaller than $300 \mathrm{~km}$ and above this radial distance thermal recombination takes over as the main loss source of this ion.

As shown in the top panel of Figure 10, the formation of $\mathrm{CH}_{3} \mathrm{OH}_{2}^{+}$is mainly due to proton transfer reaction of $\mathrm{CH}_{3} \mathrm{OH}$ with $\mathrm{H}_{3} \mathrm{O}^{+}$and $\mathrm{CH}_{4}^{+}$(see solid curves in this Fig- 

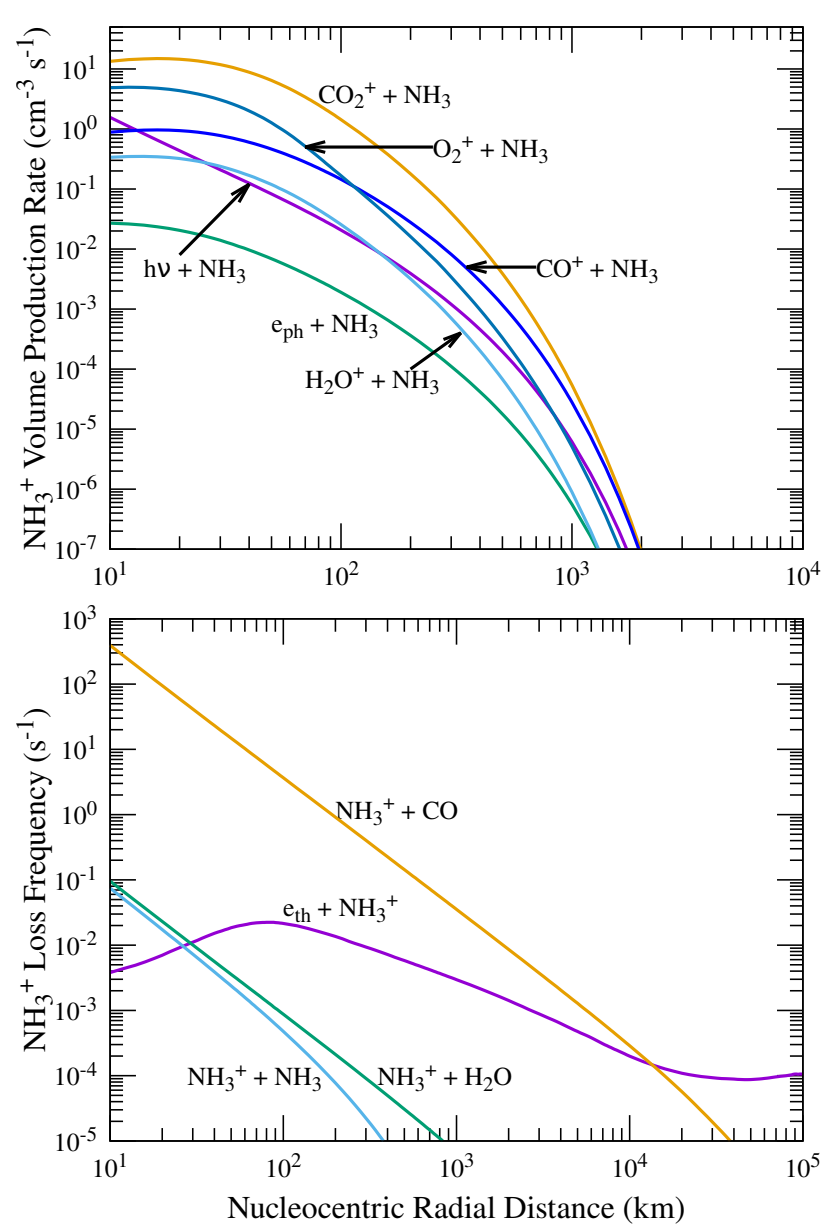

Figure 6. Modelled production rate (top panel) and loss frequency (bottom panel) profiles of $\mathrm{NH}_{3}^{+}$in the coma of comet $\mathrm{R} 2$. Input conditions are same as explained in Figure $1 . \mathrm{h} \nu, \mathrm{e}_{p h}$, and $\mathrm{e}_{t h}$ represent solar photon, photoelectron, and thermal electron, respectively.

ure). Close to the surface of nucleus, the loss of this ion is significantly controlled by charge exchange between $\mathrm{CH}_{3} \mathrm{OH}_{2}^{+}$ and $\mathrm{NH}_{3}$ which leads to $\mathrm{NH}_{4}^{+}$formation. Thermal recombination is the dominant loss source of this ion compared to collisional removal processes in the inner coma of comet C/2016 R2.

Similarly, as shown in the bottom panel of Figure 10, several proton transfer reactions are involved in the production of $\mathrm{NH}_{4}^{+}$. As explained earlier, proton transfer between $\mathrm{CH}_{3} \mathrm{OH}_{2}^{+}$and $\mathrm{NH}_{3}$ leads to the significant formation of $\mathrm{NH}_{4}^{+}$ for radial distances below $100 \mathrm{~km}$. Above this radial distance the proton transfer reactions of $\mathrm{H}_{3} \mathrm{O}^{+}, \mathrm{H}_{2} \mathrm{O}^{+}$, and $\mathrm{CH}_{4}^{+}$with $\mathrm{NH}_{3}$ are the important formation sources of $\mathrm{NH}_{4}^{+}$. Thermal recombination is the most significant loss source of this ion throughout the cometary coma.

\subsection{Production and loss mechanisms of atomic ions $\mathrm{C}^{+}$and $\mathrm{O}^{+}$}

The modelled formation and loss processes of $\mathrm{C}^{+}$in the inner coma of comet $\mathrm{C} / 2016 \mathrm{R} 2$ are presented in top and bottom panels of Figure 11, respectively. Calculations in this Figure show that the major formation of $\mathrm{C}^{+}$occurs due to the
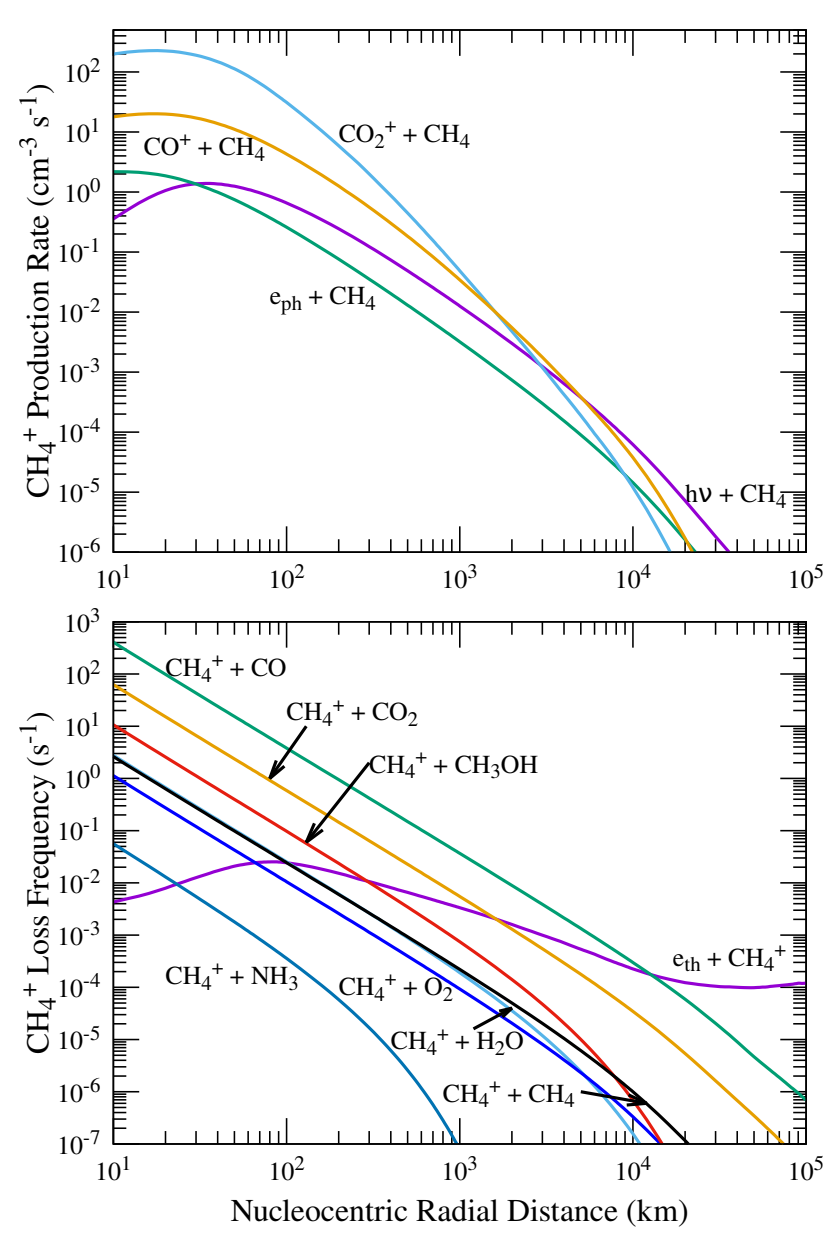

Figure 7. The production rates (top panel) and loss frequency profiles (bottom panel) of $\mathrm{CH}_{4}^{+}$in the coma of comet $\mathrm{R} 2$. Input conditions are same as explained in Figure 1. $\mathrm{h} \nu, \mathrm{e}_{p h}$, and $\mathrm{e}_{t h}$ represent solar photon, photoelectron, and thermal electron, respectively.

photoionization of $\mathrm{CO}$. Other production processes such as electron impact of $\mathrm{CO}$ and ionization of $\mathrm{CO}_{2}$ by photons and photoelectrons together contribute to about $50 \%$ of the total $\mathrm{C}^{+}$production. The calculated loss frequency profiles in the bottom panel of Figure 11 show that the collision with $\mathrm{CO}_{2}$ is the significant loss source of this ion throughout the inner coma.

Similarly, the modelled formation rate and loss frequency profiles of $\mathrm{O}^{+}$are presented in top and bottom panels of Figure 12, respectively. The production of $\mathrm{O}^{+}$is majorly due to photoionization of $\mathrm{CO}$ followed by photodissociative ionization of $\mathrm{CO}_{2}$. The contribution from other sources to the $\mathrm{O}^{+}$production rate is negligible. As shown in the bottom panel of this figure, the loss of this ion is mainly due to collisions with $\mathrm{CO}_{2}$ which leads to the formation of $\mathrm{O}_{2}^{+}$. Thermal recombination plays no significant role in the removal of this ion due to slow reaction rate.

\subsection{Time scales for ions}

The calculated time scale profiles for the chemical loss of ions, which is due to collisions between species and thermal recombination, and transport due to advection are plotted 

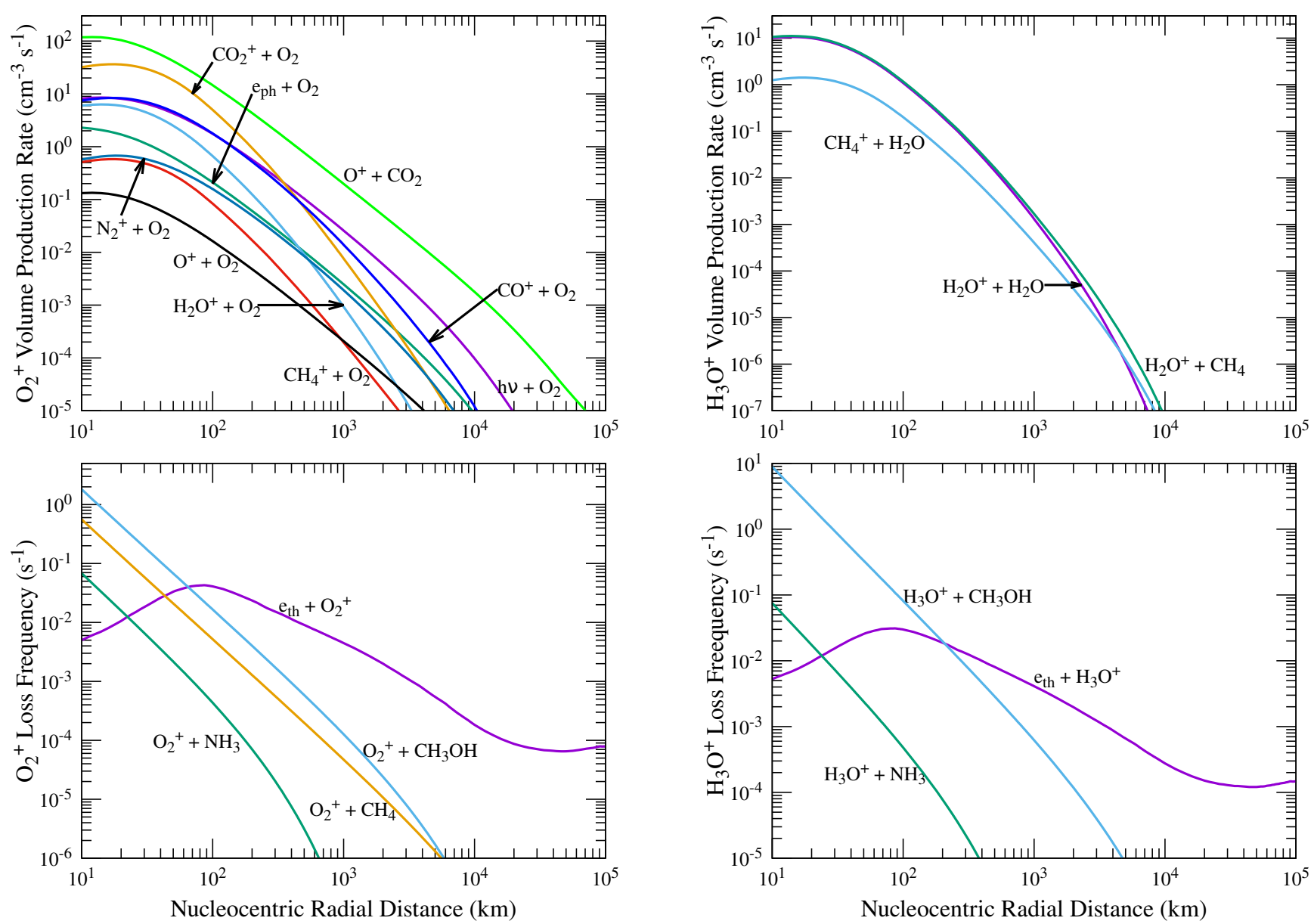

Figure 8. Modelled production rate (top panel) and loss frequency (bottom panel) profiles of $\mathrm{O}_{2}^{+}$via different mechanisms in the coma of comet $\mathrm{C} / 2016 \mathrm{R} 2$. Input conditions are same as explained in Figure 1. $\mathrm{h} \nu, \mathrm{e}_{p h}$, and $\mathrm{e}_{t h}$ represents solar photon, photoelectron, and thermal electron, respectively.

in Figure 13. Since the chemical lifetimes of most of the ions are smaller than lifetime due to transport, they are under photochemical equilibrium condition. For radial distances below $50 \mathrm{~km}, \mathrm{CH}_{3} \mathrm{OH}_{2}^{+}$and $\mathrm{NH}_{4}^{+}$have chemical lifetimes longer than the transport time scales due to significantly lower collisional reaction rates with other species (see Figure 10). The radial transport of $\mathrm{C}^{+}$and $\mathrm{O}^{+}$is important for radial distances above $5000 \mathrm{~km}$.

\subsection{Ion density distribution}

By incorporating the previously discussed formation and destruction mechanisms the ion density profiles in the inner coma of comet C/2016 R2 are computed and presented in Figure 14. These calculations show that $\mathrm{CO}_{2}^{+}$is the dominant ion for radial distances smaller than $3000 \mathrm{~km}$. But close to the nucleus, $\mathrm{CH}_{3} \mathrm{OH}^{+}, \mathrm{CH}_{3} \mathrm{OH}_{2}^{+}$, and $\mathrm{O}_{2}^{+}$are also important ions. The peak density occurs at a radial distance around $100 \mathrm{~km}$ with $\mathrm{CO}_{2}^{+}$as dominant ion. Above a radial distance of $3000 \mathrm{~km} \mathrm{CO}^{+}$is the dominant ion in the inner coma.

\subsection{Volume emission rates and emission intensity ratios}

Figure 15 shows the calculated volume emission rate profiles for different excited states of $\mathrm{CO}_{2}^{+}, \mathrm{CO}^{+}, \mathrm{H}_{2} \mathrm{O}^{+}$, and $\mathrm{N}_{2}^{+}$. Photoionization and photoelectron impact ionization of corresponding neutrals are the important sources for the formation excited states of these ions for radial distances smaller than $300 \mathrm{~km}$. Above these radial distances solar resonance fluorescence is the dominant excitation source. Close to the surface of the nucleus the electron impact ionization excitation is also a significant source for the excited states of ions.

We present the measured and modelled emission intensity ratios of $\mathrm{N}_{2}^{+} / \mathrm{CO}^{+}$and $\mathrm{CO}_{2}^{+} / \mathrm{CO}^{+}$in comet $\mathrm{C} / 2016$ $\mathrm{R} 2$ as a function of the nucleocentric projected distance in Figure 16. In this Figure, the $\mathrm{H}_{2} \mathrm{O}^{+} / \mathrm{CO}^{+}$upper limit is also indicated. The solid curves in this figure are the modelled emission intensity ratios by accounting for ionization of neutrals by solar photons and photoelectrons, and also resonance fluorescence excitation, which we call a standard case. The computed intensity ratios (solid curves) are consistent with the observations within a factor 2 for $\mathrm{CO}_{2}^{+} / \mathrm{CO}^{+}$ 

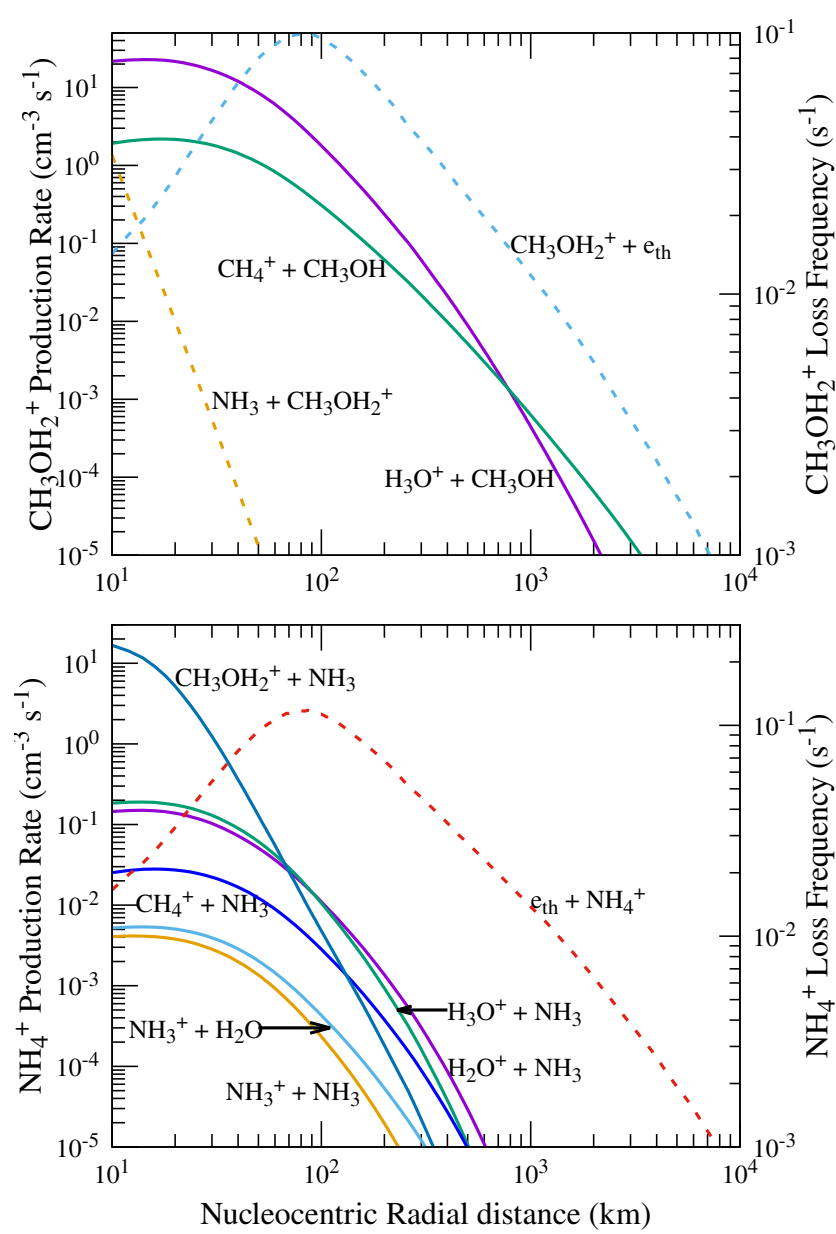

Figure 10. Calculated production rate and loss frequency profiles of $\mathrm{CH}_{3} \mathrm{OH}_{2}^{+}$(top panel) and $\mathrm{NH}_{4}^{+}$(bottom panel). Loss frequency profiles are plotted with dashed curves with scale on right $y$ axis. Input conditions are the same as explained in Figure 1. $\mathrm{e}_{t h}$ represents the thermal electron.

and $50 \%$ for $\mathrm{N}_{2}^{+} / \mathrm{CO}^{+}$. Our calculated $\mathrm{H}_{2} \mathrm{O}^{+} / \mathrm{CO}^{+}$emission intensity ratio profile is smaller by more than one order of magnitude compared to the derived upper limit of the observation.

We have also done several case studies to explore the impact of different excitation processes on the modelled ion emission intensity ratios. The implications of these calculations are discussed in the later section. When we consider only photon and electron impact ionization and excitation of neutrals, the modelled $\mathrm{N}_{2}^{+} / \mathrm{CO}^{+}$emission intensity ratio is significantly decreased by a factor of 5 or more compared to the standard case (see red dashed line in Figure 16). In this case, the modelled $\mathrm{CO}_{2}^{+} / \mathrm{CO}^{+}$emission intensity ratio profile is higher by a factor of about 2 for radial distances below $300 \mathrm{~km}$, whereas, it is higher by an order of magnitude at large radial distances compared to standard case (see black dashed curve in Figure 16). By neglecting the resonance fluorescence excitation mechanism, the modelled $\mathrm{H}_{2} \mathrm{O}^{+} / \mathrm{CO}^{+}$ emission intensity ratio profile is nearly consistent with the standard case (see blue dashed curve in Figure 16). We also calculated ion emission intensity ratio profiles by accounting for resonance fluorescence as the only excitation mechanism. As shown in Figure 16, the modelled $\mathrm{H}_{2} \mathrm{O}^{+} / \mathrm{CO}^{+}$
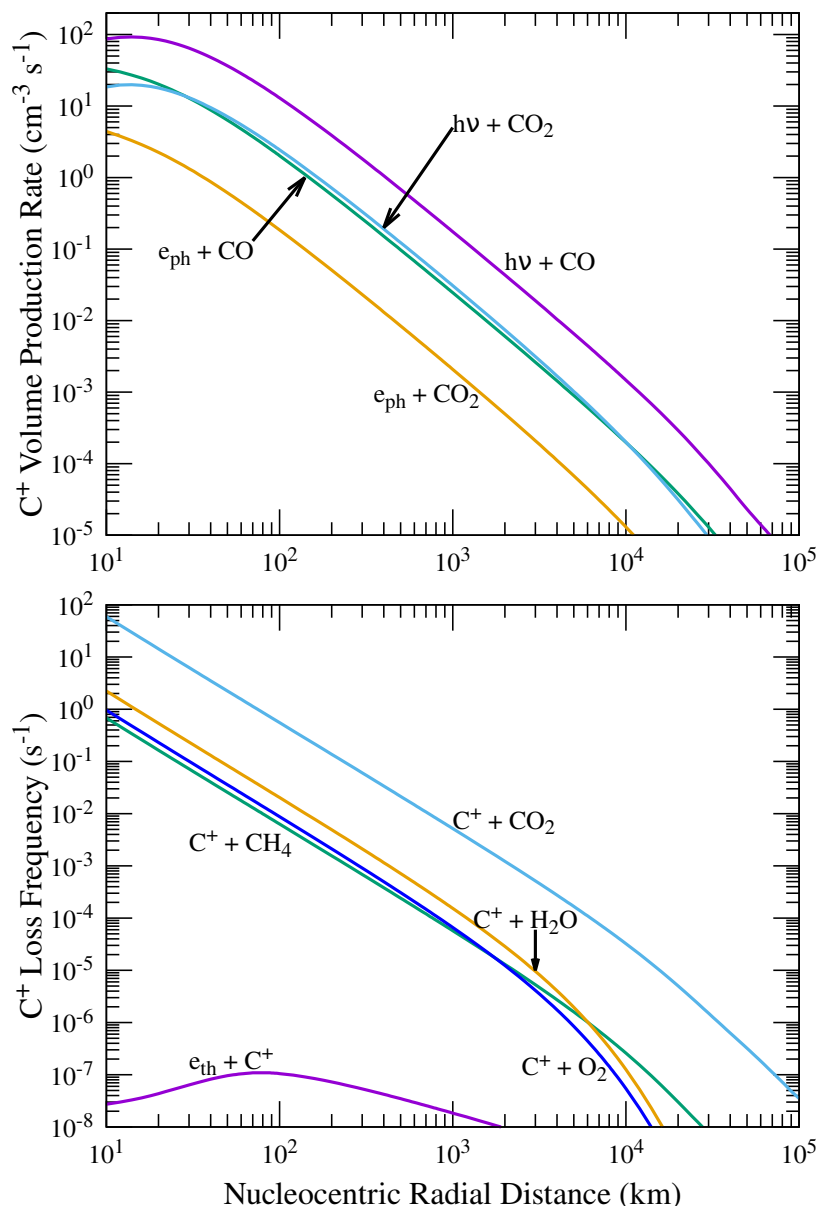

Figure 11. Modelled production rate (top panel) and loss frequency profiles (bottom panel) of $\mathrm{C}^{+}$in comet C/2016 R2. Input conditions are the same as explained in Figure 1. $\mathrm{h} \nu, \mathrm{e}_{p h}$, and $\mathrm{e}_{t h}$ represent solar photon, photoelectron, and thermal electron, respectively.

(see blue dotted curve), $\mathrm{CO}_{2}^{+} / \mathrm{CO}^{+}$(see black dotted curve), $\mathrm{N}_{2}^{+} / \mathrm{CO}^{+}$(see red dotted curve) emission intensity ratios are in agreement with our standard case values.

\section{DISCUSSION}

\subsection{Ion-neutral chemistry in CO-dominated coma}

In a water-dominated cometary coma, photoionization of $\mathrm{H}_{2} \mathrm{O}$ produces $\mathrm{H}_{2} \mathrm{O}^{+}$and the collisions between the former and later species lead to the formation of $\mathrm{H}_{3} \mathrm{O}^{+}$. Even with a small mixing ratio (about 1\%), the molecules having higher proton affinity can quickly react with $\mathrm{H}_{3} \mathrm{O}^{+}$and produce $\mathrm{NH}_{4}^{+}$and $\mathrm{CH}_{3} \mathrm{OH}_{2}^{+}$as the dominant ions in the inner coma (Haider \& Bhardwaj 2005; Vigren \& Galand 2013; Heritier et al. 2017). But our modelled density profiles in Figure 14 show that the ion composition in the inner coma of comet $\mathrm{C} / 2016 \mathrm{R} 2$ is completely different when compared to a regular water-dominated comet. This unusual ionospheric composition is mainly due to the peculiar neutral composition of cometary coma. Unlike other comets, comet C/2016 R2 coma is dominantly composed of $\mathrm{CO}$ and remarkably depleted in water. In this peculiar coma composition, the modelled ion density profiles show that $\mathrm{CO}_{2}^{+}$is the dominant ion 

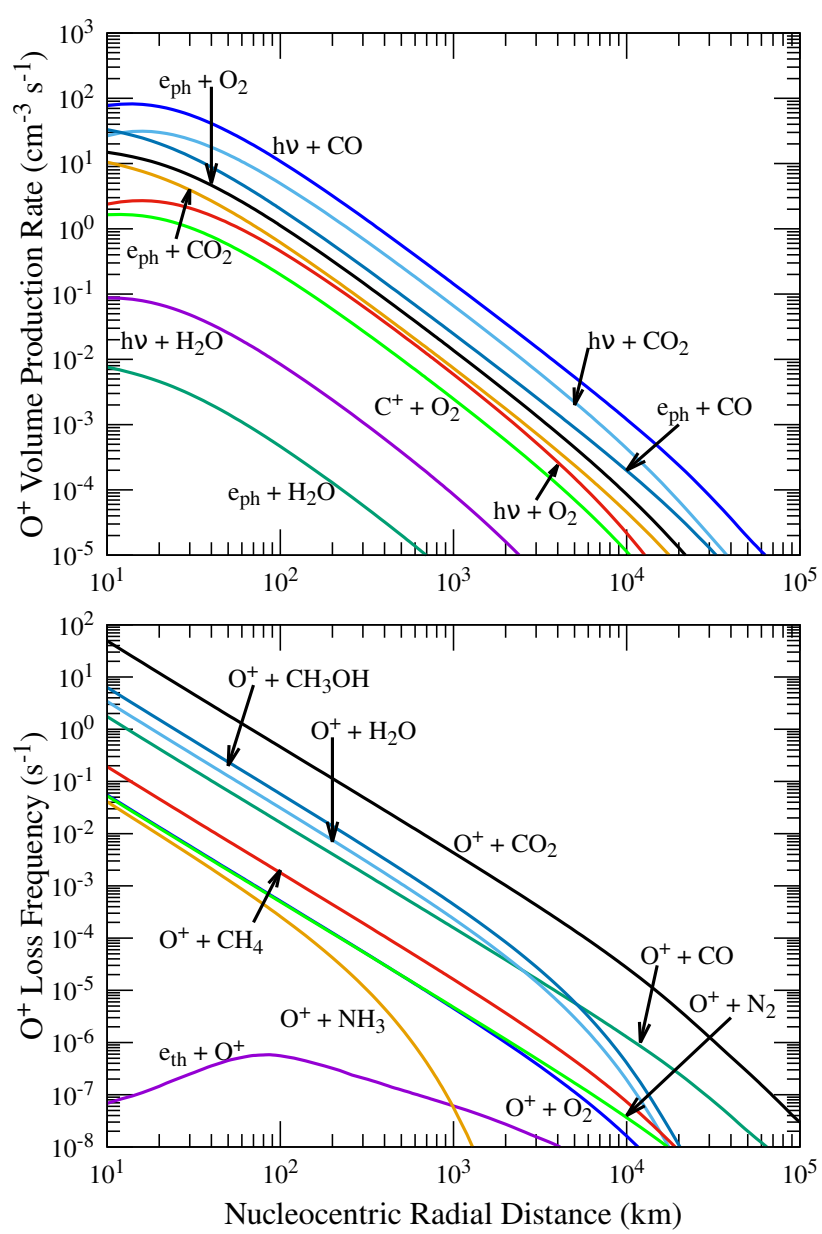

Figure 12. Calculated production rate (top panel) and loss frequency profiles (bottom panel) of $\mathrm{O}^{+}$in comet C/2016 R2. Input conditions are the same as explained in Figure 1. $\mathrm{h} \nu, \mathrm{e}_{p h}$, and $\mathrm{e}_{t h}$ represent solar photon, photoelectron, and thermal electron, respectively.

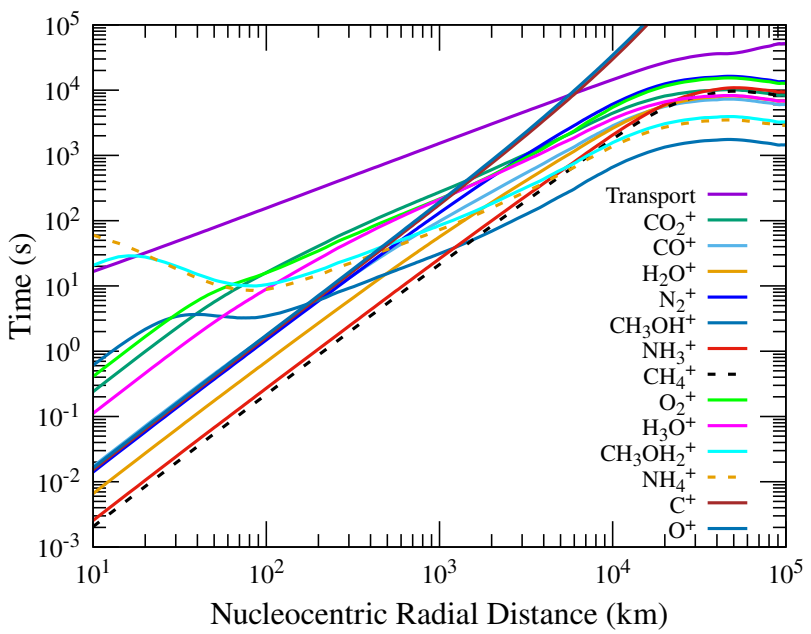

Figure 13. Calculated lifetime profiles of different ions due to transport and chemical reactions in C/2016 R2. Input conditions are the same as explained in Figure 1.

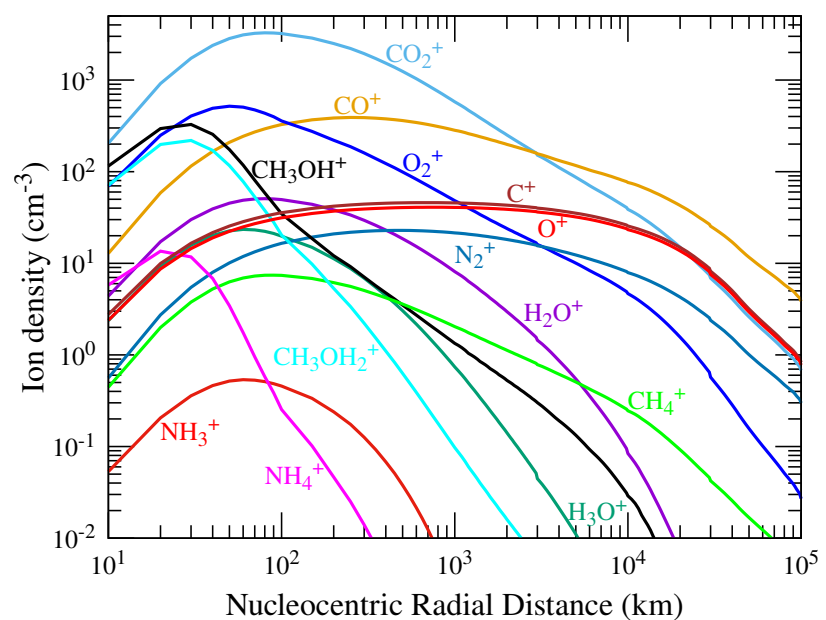

Figure 14. The modelled density profiles for different ions in the coma of comet $\mathrm{C} / 2016 \mathrm{R} 2$. Input conditions are the same as explained in Figure 1.

for radial distances below $3000 \mathrm{~km}$, with a peak ion density at around $100 \mathrm{~km}$, whereas the $\mathrm{CO}^{+}$density is significant for radial distances above $5000 \mathrm{~km}$ (see Figure 14).

The $\mathrm{CO}_{2}^{+}$and $\mathrm{CO}^{+}$ion distribution can be explained based on their corresponding formation and destruction processes in the inner coma. The loss of $\mathrm{CO}^{+}$mainly depends on the collisions with $\mathrm{CO}_{2}$, which is the major formation channel for $\mathrm{CO}_{2}^{+}$for radial distances smaller than $10^{3} \mathrm{~km}$ (see Figures 2). But the loss of $\mathrm{CO}_{2}^{+}$significantly depends on the thermal recombination except for the radial distances smaller than $100 \mathrm{~km}$. Our model calculation show that the destruction rate of $\mathrm{CO}^{+}$is more than an order of magnitude higher compared to that of $\mathrm{CO}_{2}^{+}$for radial distances smaller than $1000 \mathrm{~km}$ (see the lower panels of Figures 1 and 2). These calculations suggest that the collisions between $\mathrm{CO}^{+}$and $\mathrm{CO}_{2}$ strongly control both the $\mathrm{CO}^{+}$and $\mathrm{CO}_{2}^{+}$densities for radial distances smaller than $1000 \mathrm{~km}$, whereas above this distance thermal recombination rates of these ions, which are nearly the same, determine the modelled ion densities. Our model calculations also show that the chemical loss of $\mathrm{CO}^{+}$, via $\mathrm{CO}_{2}$ collisions, produces $\mathrm{CO}_{2}^{+}$ about an order of magnitude more efficiently than photoionization of $\mathrm{CO}_{2}$. Thus, the significant collisional loss of $\mathrm{CO}^{+}$ substantially reduces its density in the coma and also leads to $\mathrm{CO}_{2}^{+}$as the dominant ion. Above $1000 \mathrm{~km}$ radial distance, $\mathrm{CO}^{+}$is the dominant ion due to its higher formation rate compared to that of $\mathrm{CO}_{2}^{+}$. Due to its endothermic nature, the charge transfer reaction between $\mathrm{CO}_{2}^{+}$and $\mathrm{CO}$ does not occur hence, $\mathrm{CO}_{2}^{+}$can not be removed by the collisions with $\mathrm{CO}$ in the cometary coma.

The modelled ion density profiles suggest that close to the nucleus surface, besides $\mathrm{CO}_{2}^{+}, \mathrm{CH}_{3} \mathrm{OH}^{+}, \mathrm{CH}_{3} \mathrm{OH}_{2}^{+}$and $\mathrm{O}_{2}^{+}$are also important ions with significant densities. The larger abundance of $\mathrm{CO}_{2}$ in the coma and the collision reaction of $\mathrm{O}^{+}$with former species significantly produce $\mathrm{O}_{2}^{+}$below $100 \mathrm{~km}$. Though we assumed a relatively large amount of $\mathrm{O}_{2}$ compared to several other detected species in this comet ( $1 \%$ of $\mathrm{CO}$ production rate), the calculations in top panel of Figure 8 show that photoionization of $\mathrm{O}_{2}$ plays no role in determining the $\mathrm{O}_{2}^{+}$density. For radial distances below 100 

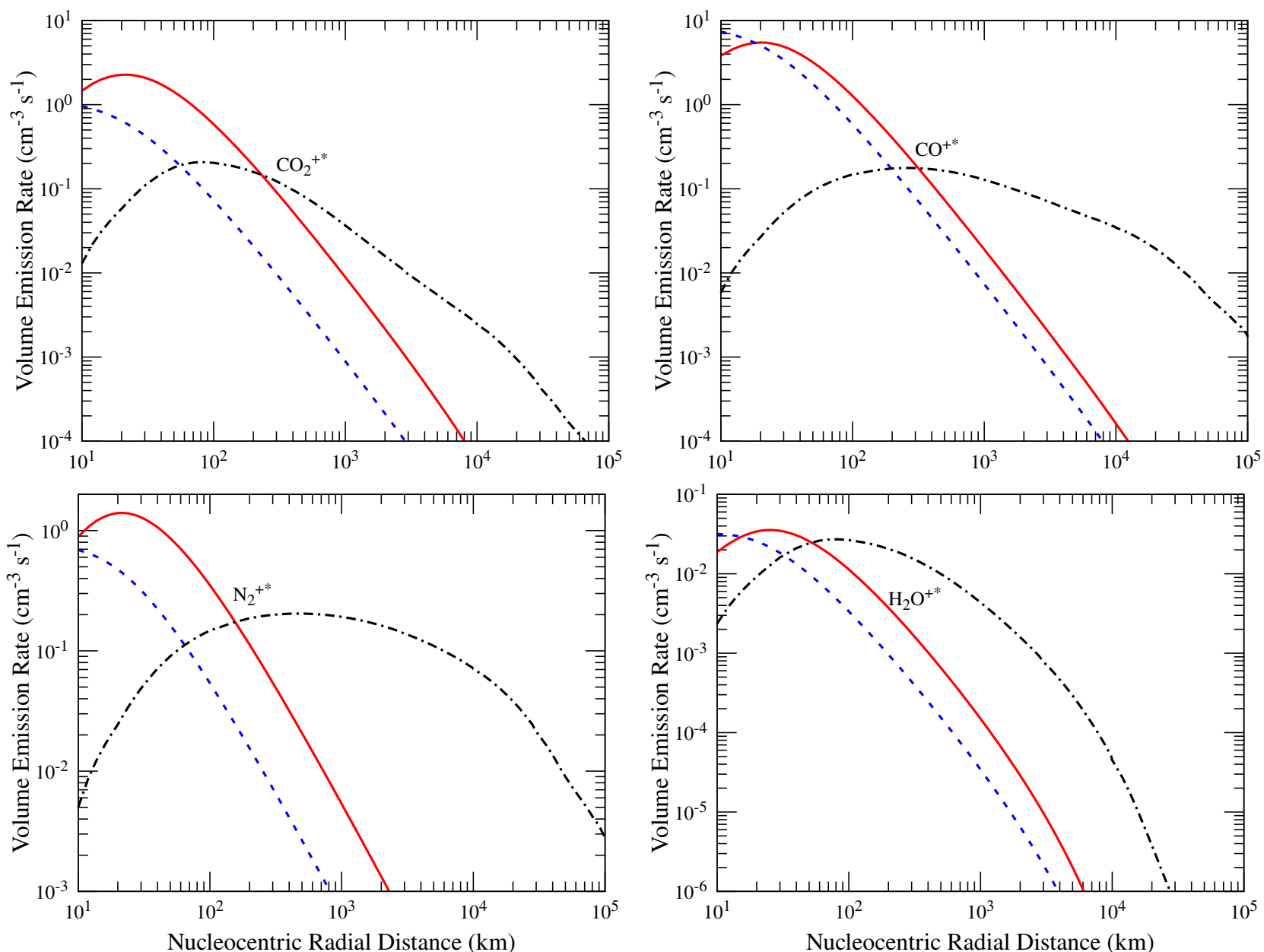

Figure 15. Modelled volume emission rates for $\mathrm{CO}_{2}^{+}(0-0)$ (top left), $\mathrm{CO}^{+}(2-0)$ (top right), $\mathrm{N}_{2}^{+}(0-0)$ (bottom left), and $\mathrm{H}_{2} \mathrm{O}^{+}(8-0)$ (bottom right) transitions. Solid red, dashed blue, and dash-dotted black curves represent the modelled volume emission rate profiles due to photoionization, electron impact ionization, and solar resonance fluorescence of corresponding neutrals and ions, respectively. Input conditions are the same as explained in Figure 1.

$\mathrm{km}$, the formation rates of $\mathrm{O}_{2}^{+}$via charge exchange between $\mathrm{CO}_{2}^{+}$and $\mathrm{O}_{2}$, and photoionization of $\mathrm{O}_{2}$ are smaller by a factor 3 and 10 compared to formation rate via charge exchange between $\mathrm{O}^{+}$and $\mathrm{CO}_{2}$, respectively (see Figure 8). By varying the $\mathrm{O}_{2}$ relative abundance between 1 and $3 \%$ with respect to the $\mathrm{CO}$ production rate no significant change in the modelled $\mathrm{O}_{2}^{+}$ion density is observed. These calculations show that the formation of $\mathrm{O}_{2}^{+}$is possible due to the collisional chemistry even in the absence of $\mathrm{O}_{2}$ in the $\mathrm{C} / 2016$ $\mathrm{R} 2$ inner coma. Hence, our assumed $\mathrm{O}_{2}$ relative abundance has no impact on the modelled $\mathrm{O}_{2}^{+}$ion density.

For radial distances below $100 \mathrm{~km}$, the contribution due to charge exchange between $\mathrm{O}_{2}^{+}$and $\mathrm{CH}_{3} \mathrm{OH}$ leads to a significant amount of $\mathrm{CH}_{3} \mathrm{OH}^{+}$formation when compared to that due to the photoionization of $\mathrm{CH}_{3} \mathrm{OH}$ (see Figure 5). The strong proton affinity between $\mathrm{CH}_{3} \mathrm{OH}^{+}$and $\mathrm{H}_{2} \mathrm{O}$ leads to $\mathrm{CH}_{3} \mathrm{OH}_{2}^{+}$as an important ion close to the surface of the nucleus (see Figure 10). All these calculations suggest that for radial distances below $100 \mathrm{~km}$, the $\mathrm{CO}_{2}^{+}, \mathrm{CH}_{3} \mathrm{OH}^{+}$, $\mathrm{CH}_{3} \mathrm{OH}_{2}^{+}$, and $\mathrm{O}_{2}^{+}$ion densities are significantly determined by collisional chemistry among the neutral species and ions rather than photon and electron impact driven processes.

The ion density profiles of $\mathrm{N}_{2}^{+}, \mathrm{C}^{+}$, and $\mathrm{O}^{+}$are almost constant for radial distances between 100 and $10^{4} \mathrm{~km}$. This can be explained on the basis of their corresponding production and loss mechanisms. The ground state energy of $\mathrm{N}_{2}^{+}$is $15.57 \mathrm{eV}$, which is the largest among the considered ions. Hence, this ion can interact with most of the neutral species via charge exchange mechanism. Our modelled loss frequency profiles show that $\mathrm{N}_{2}^{+}$ion interacts strongly with $\mathrm{CO}$ and $\mathrm{CO}_{2}$ for the radial distances up to $3 \times 10^{3} \mathrm{~km}$. Though $\mathrm{CO}_{2}$ is less abundant than $\mathrm{CO}$ in the coma, the modelled charge exchange rate of $\mathrm{N}_{2}^{+}$with $\mathrm{CO}_{2}$ is comparable to that with $\mathrm{CO}$ (see the lower panel of Figure 4). This is because the rate coefficient for the charge exchange between $\mathrm{N}_{2}^{+}$and $\mathrm{CO}_{2}$ is higher by about an order of magnitude compared to that of $\mathrm{N}_{2}^{+}$and $\mathrm{CO}$ (see the reaction rates of R50 and R55 in Table A1). Hence, the strong collisional interaction of $\mathrm{N}_{2}^{+}$with major species in the coma makes the density profile of this ion almost constant for radial distances between 100 and $10^{4} \mathrm{~km}$. Similarly, the constant $\mathrm{C}^{+}$ and $\mathrm{O}^{+}$ion density profiles are also due to strong collisional interaction of these ions with $\mathrm{CO}_{2}$ for radial distances up to $10^{4} \mathrm{~km}$ (see the lower panel of Figures 11 and 12).

As explained earlier, in a water dominated comet, the protonated ions such as $\mathrm{H}_{3} \mathrm{O}^{+}, \mathrm{NH}_{4}^{+}$, and $\mathrm{CH}_{3} \mathrm{OH}_{2}^{+}$are sig- 


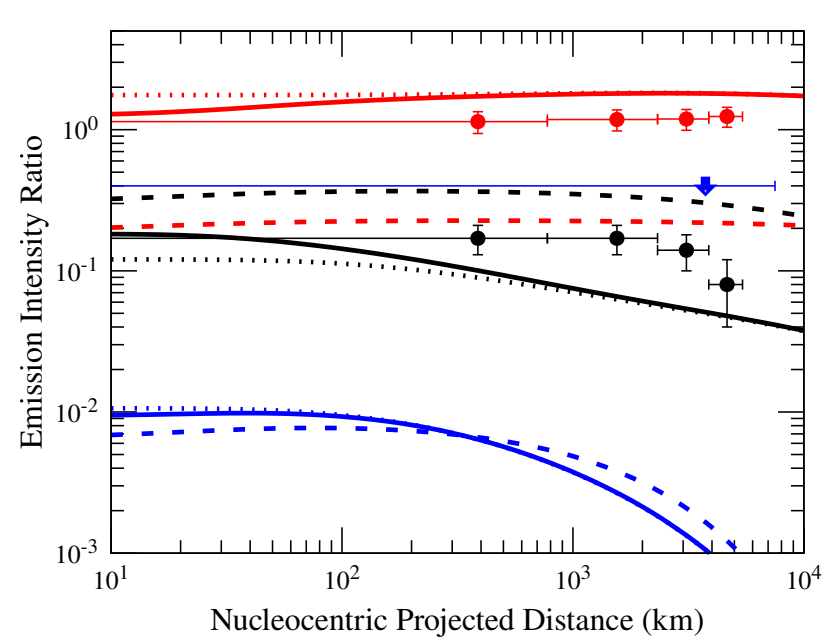

Figure 16. Modelled emission intensity ratios of $\mathrm{N}_{2}^{+} / \mathrm{CO}^{+}$(red), $\mathrm{CO}_{2}^{+} / \mathrm{CO}^{+}$(black), and $\mathrm{H}_{2} \mathrm{O}^{+} / \mathrm{CO}^{+}$(blue) as a function of projected distance. Solid curves are the modelled ratio profiles by accounting for ionization and excitation neutral species by photons and photoelectrons, and solar resonance fluorescence excitation mechanisms. Dashed and dotted curves represents the modelled emission intensity ratios profiles by accounting for only ionization of neutrals and only solar resonance fluorescence mechanisms, respectively. The observed flux ratios are plotted with corresponding colours with vertical error bars. The blue horizontal line with a downward arrow represents the derived upper limit of $\mathrm{H}_{2} \mathrm{O}^{+} / \mathrm{CO}^{+}$emission intensity ratio. Input conditions are the same as explained in Figure 1.

nificantly controlled by $\mathrm{H}_{2} \mathrm{O}$. Photoionization of $\mathrm{H}_{2} \mathrm{O}$ is the primary reaction that produces $\mathrm{H}_{2} \mathrm{O}^{+}$and further interaction of this ion with neutral species drives the collisional chemistry of protonated ions in the water-dominated coma. But in the case of comet $\mathrm{C} / 2016 \mathrm{R} 2$, which is a water-poor comet, the $\mathrm{H}_{2} \mathrm{O}^{+}$ion density for radial distances below 1000 $\mathrm{km}$ is controlled by $\mathrm{CO}$ and $\mathrm{CO}_{2}$ densities, rather than photoionization of $\mathrm{H}_{2} \mathrm{O}$. As shown by our calculations, for radial distances smaller than $1000 \mathrm{~km}$, the major formation $\mathrm{H}_{2} \mathrm{O}^{+}$ is due to the charge exchange between $\mathrm{CO}_{2}^{+}$and $\mathrm{H}_{2} \mathrm{O}$ rather than photoionization of $\mathrm{H}_{2} \mathrm{O}$. Similarly, $\mathrm{CO}$ also plays an important role in removing the $\mathrm{H}_{2} \mathrm{O}^{+}$for radial distances smaller than $5000 \mathrm{~km}$ in the inner coma (see Figure 3). This $\mathrm{H}_{2} \mathrm{O}^{+}$ion chemistry, which is primarily driven by $\mathrm{CO}_{2}$ and $\mathrm{CO}$, further initiates the formation of $\mathrm{H}_{3} \mathrm{O}^{+}$via proton transfer reactions of $\mathrm{H}_{2} \mathrm{O}^{+}$with $\mathrm{H}_{2} \mathrm{O}$ and $\mathrm{CH}_{4}$. Due to high proton affinity, the collisions between $\mathrm{CH}_{3} \mathrm{OH}$ and $\mathrm{H}_{3} \mathrm{O}^{+}$ results in $\mathrm{CH}_{3} \mathrm{OH}_{2}^{+}$which further interact with $\mathrm{NH}_{3}$ that leads to the formation of $\mathrm{NH}_{3}^{+}$for radial distances below $100 \mathrm{~km}$ (see Figures 9 and 10). Hence, unlike $\mathrm{H}_{2} \mathrm{O}$ driven ion-neutral chemistry in normal comets, in comet $\mathrm{C} / 2016$ $\mathrm{R} 2, \mathrm{CO}$ and $\mathrm{CO}_{2}$ play an important role in the formation of protonated ions.

The role of $\mathrm{CO}_{2}$ is crucial in determining the ionchemistry in this comet. Neutral density of $\mathrm{CO}_{2}$ controls the total loss frequencies and subsequently the ion densities of $\mathrm{CO}^{+}, \mathrm{N}_{2}^{+}, \mathrm{C}^{+}$, and $\mathrm{O}^{+}$for radial distances below 1000 $\mathrm{km}$, whereas the neutral density of $\mathrm{CO}$ significantly controls the loss rates of $\mathrm{H}_{2} \mathrm{O}^{+}, \mathrm{NH}_{3}^{+}$, and $\mathrm{CH}_{4}^{+}$ions. Hence, any change in the abundances of $\mathrm{CO}_{2}$ and $\mathrm{CO}$ can significantly alter the total ion composition in the inner coma of this comet.

\subsection{Derivation of neutrals densities from the observed ion emission intensities}

Assuming solar resonance fluorescence is the only excitation mechanism, the observed flux ratios of ionic emissions are converted into ion density ratios and assumed to be equal to their respective neutral density ratios in the C/2016 R2 coma (Cochran \& McKay 2018; Wierzchos \& Womack 2018; Biver et al. 2018; McKay et al. 2019). But none of these works account for the ionization and excitation of neutrals by photons and photoelectrons which can also produce the observed emissions. Here we discuss the derivation of neutral density ratio based on observed corresponding ion emission intensity ratio using our modelled emission processes in the inner coma.

\subsubsection{Role of ionization and excitation processes in determining the ion emission intensity ratios}

The ionization and excitation of neutrals by solar photons and photoelectrons can spontaneously produce the observed emissions of ions. If these are the only emission mechanisms in the cometary coma, then the observed intensity ratios can be directly used to constrain the corresponding neutral density ratio. If the solar resonance fluorescence is the only excitation mechanism, then the distribution of ion densities in the coma and the excitation factors (g-factors) determine the observed emission intensity ratio. Since the observed ion emissions are determined by both ionization and excitation of neutrals and resonance fluorescence of ions, it is essential to understand the photochemistry of cometary coma, which determines the ion density distribution, in order to derive the mixing ratios of neutral densities based on the observed ion emission intensity ratio. Our calculations in Figure 15 show that for radial distances smaller than 300 $\mathrm{km}$, the modelled volume emission rates of $\mathrm{CO}^{+}, \mathrm{CO}_{2}^{+}, \mathrm{N}_{2}^{+}$, and $\mathrm{H}_{2} \mathrm{O}^{+}$due to ionization and excitation of corresponding neutrals by photons and photoelectrons are higher by several orders of magnitude compared to those due to solar resonance fluorescence. This calculation suggests that ionization and excitation of neutrals alone can also determine the observed emission intensity ratio.

When we account for ionization and excitation of neutrals and resonance fluorescence excitation mechanism, our modelled emission intensity ratios of $\mathrm{CO}_{2}^{+} / \mathrm{CO}^{+}$and $\mathrm{N}_{2}^{+} / \mathrm{CO}^{+}$are consistent with the measured emission ratios within a factor of 2 (see solid red and black curves in Figure 16). In the case of $\mathrm{H}_{2} \mathrm{O}^{+} / \mathrm{CO}^{+}$, the modelled emission ratio is smaller by two orders of magnitude compared to the derived upper limit from the observation. Our modelled volume emissions rates in Figure 15 show that the ionization and excitation of $\mathrm{N}_{2}$ and $\mathrm{CO}$ can also produce the corresponding ionic emissions in the cometary coma. Hence, to assess the role of ionization and excitation of neutrals on the modelled ion emission ratios, we neglected the resonance fluorescence excitation. In this case, the modelled $\mathrm{N}_{2}^{+} / \mathrm{CO}^{+}$ emission intensity ratio is smaller by a factor of 5 compared to the observation (see red dashed line in Figure 16). But when we account for resonance fluorescence as the only excitation mechanisms, the modelled $\mathrm{N}_{2}^{+} / \mathrm{CO}^{+}$emission inten- 
sity ratio is consistent with the observation (see red dotted curve in Figure 16). This is mainly because the contribution from ionization and excitation of $\mathrm{CO}$ and $\mathrm{N}_{2}$ to the total volume emission rate reduces rapidly for radial distances above $300 \mathrm{~km}$ whereas, the resonance fluorescence takes over the major excitation source (see Figure 15). Hence, the observed emission ratio is significantly controlled by resonance fluorescence rather than the remaining excitation processes.

By accounting for ionization and excitation of neutral and also resonance fluorescence mechanisms, we find the calculated $\mathrm{CO}_{2}^{+} / \mathrm{CO}^{+}$emission intensity ratio decreases for projected distances above $300 \mathrm{~km}$. This can be explained based on the modelled volume emission rates of these ions. As shown in Figure 15, at larger radial distances $\left(>10^{3} \mathrm{~km}\right)$, the volume emission rate of $\mathrm{CO}_{2}^{+}$is smaller by more than an order of magnitude compared to that of $\mathrm{CO}^{+}$, which is mainly due to the radial density distribution of these ions. Hence, the higher $\mathrm{CO}^{+}$ion density at larger radial distances reduces the modelled $\mathrm{CO}_{2}^{+} / \mathrm{CO}^{+}$emission intensity ratio, as can be noticed in the observation. When we only account for ionization excitation processes of neutrals, the modelled ion emission intensity ratio of $\mathrm{CO}_{2}^{+} / \mathrm{CO}^{+}$is closer to the observed profile for the radial distances below $2000 \mathrm{~km}$ (see black dashed curve in Figure 16). However, the decrease in the observed $\mathrm{CO}_{2}^{+} / \mathrm{CO}^{+}$emission intensity ratio for projected distances larger than $2000 \mathrm{~km}$ can not be explained by only ionization and excitation processes. All these calculations suggest that resonance fluorescence excitation plays a more significant role in determining the observed $\mathrm{CO}_{2}^{+} / \mathrm{CO}^{+}$ emission intensity ratio than ionization and excitation of neutrals at large radial distances.

Due to lack of measured branching ratios, we assumed $50 \%$ of electron impact ionization of $\mathrm{H}_{2} \mathrm{O}$ producing $\mathrm{H}_{2} \mathrm{O}^{+}$ in the $\widetilde{A}^{2} \mathrm{~A}_{1}$ excited state. By increasing our assumed branching ratio to $100 \%$, no significant change in the modelled $\mathrm{H}_{2} \mathrm{O}^{+} / \mathrm{CO}^{+}$emission intensity ratio is found. This calculation suggests that solar photons significantly determine the ion emission intensity ratio rather than electron impact ionization and excitation of $\mathrm{H}_{2} \mathrm{O}$. The calculation in Figure 16 show that the modelled $\mathrm{H}_{2} \mathrm{O}^{+} / \mathrm{CO}^{+}$emission intensity ratio does not vary significantly by accounting for only resonance fluorescence and/or ionization excitation of neutrals. This suggests that the ionization and excitation of neutrals play an equal role in determining the modelled $\mathrm{H}_{2} \mathrm{O}^{+} / \mathrm{CO}^{+}$emission intensity ratio compared to the role of solar resonance fluorescence excitation mechanism.

\subsubsection{Derivation of neutral density based on the $\mathrm{N}_{2}^{+} / \mathrm{CO}^{+}$ emission intensity ratio}

Cochran \& McKay (2018) converted the observed emission flux ratio of $\mathrm{N}_{2}^{+} / \mathrm{CO}^{+}$to $\mathrm{N}_{2} / \mathrm{CO}$ neutral density ratio based on the approach of Lutz et al. (1993) and Wyckoff \& Heyd (2003). It should be noticed that Lutz et al. (1993) and Wyckoff \& Heyd (2003) observed these ionic emissions on cometary tail regions where the photoionization excitation processes are not significant compared to resonance fluorescence. Our modelled volume emission rate profiles also show that at larger radial distances emission intensity is mainly determined by resonance fluorescence excitation mechanism. Hence, the observed $\mathrm{N}_{2}^{+} / \mathrm{CO}^{+}$emission ion intensity ratio can be used to derive their respective neutral density ratio.
But for radial distances below $100 \mathrm{~km}$, the photon and electron impact ionization and excitation of neutral species significantly controls the observed $\mathrm{N}_{2}^{+} / \mathrm{CO}^{+}$ratio. Thus, only the observed emission intensity ratios of these ions at larger radial distances are suitable to derive their respective neutral abundance ratio.

As discussed earlier, the densities of $\mathrm{N}_{2}^{+}$and $\mathrm{CO}^{+}$at large radial distances $\left(>10^{3} \mathrm{~km}\right)$ are essentially governed by photoionization of corresponding neutrals and thermal recombination (see Figures 2 and 4 ). The electron temperature, which determines the recombination rates of these ions and consequently their density, can influence the modelled emission intensity ratios. In the model we assumed electron temperature $\left(T_{e}\right)$ in the coma equivalent to that of neutral temperature, which is calculated by Ip (1983). This assumption causes a discrepancy between the modelled and observed $\mathrm{N}_{2}^{+} / \mathrm{CO}^{+}$emission ratios of about a factor 2 (See Figure 16). Due to lower cooling rates, it is expected that the electron temperatures at larger radial distances can be much higher than our assumed value (Gan \& Cravens 1990). In order to evaluate the role of electron temperature on the modelled ion emission intensity ratio, we used the electron temperature profile for $1 \mathrm{P} /$ Halley from Eberhardt \& Krankowsky (1995), which is determined from Giotto measurements. We noticed that at larger radial distances, the Ip (1983) calculated neutral temperature is several orders of magnitude smaller than the electron temperature derived by Eberhardt \& Krankowsky (1995). By using the temperature profile of comet $1 \mathrm{P} /$ Halley in the model, we find that the modelled $\mathrm{N}_{2}^{+} / \mathrm{CO}^{+}$emission intensity ratio profile decreases by a factor 2 and is then consistent with the observation. This calculation suggests that electron temperature can also play an important role in determining the observed emission intensity ratio. Modelling the electron temperature profile in this CO-dominated cometary coma is beyond the scope of the present work.

Using the modelled photoionization and recombination rates, we derive the following analytical expression to convert the observed flux ratio into neutral density ratio :

$\frac{\left[N_{2}\right]}{[C O]}=\frac{I_{N_{2}^{+}}}{I_{C O^{+}}} \times 1.69 \times 10^{-2} \times T_{e}^{0.16}$

The derivation of the above expression is provided in Appendix C. By substituting our observed flux ratio $\left(\mathrm{I}_{N_{2}^{+}} / \mathrm{I}_{C O^{+}}\right)$in the above equation and for an electron temperature of $1000 \mathrm{~K}$, we obtained the neutral density ratio of $\left[\mathrm{N}_{2}\right] /[\mathrm{CO}]$ as 0.06 , which is consistent with the derived volume mixing ratio of $\mathrm{N}_{2}$ from the other observations. It should be noted that larger electron temperature can lead to a higher abundance ratio of neutral species.

\subsubsection{Derivation of neutral density based on the $\mathrm{CO}_{2}^{+} / \mathrm{CO}^{+}$emission intensity ratio}

It should be noticed that by accounting for $18 \%$ of $\mathrm{CO}_{2}$ relative to the $\mathrm{CO}$ production rate (based on the observations of McKay et al. 2019), the modelled $\mathrm{CO}_{2}^{+} / \mathrm{CO}^{+}$ion density ratio significantly varies for radial distances below $10^{4}$ $\mathrm{km}$ (see Figure 14). As explained earlier, both the $\mathrm{CO}_{2}^{+}$and $\mathrm{CO}^{+}$ion densities are significantly controlled by ion-neutral chemistry rather than photoionization and thermal recombination processes for the radial distances below $1000 \mathrm{~km}$ 
(see Sections 4.1 and 4.2). Hence, the conversion of observed $\mathrm{CO}_{2}^{+} / \mathrm{CO}^{+}$emission flux ratio to corresponding neutral density ratio leads to an overestimation of the $\mathrm{CO}_{2}$ abundance in the coma.

Our modelled volume emission rates of $\mathrm{CO}^{+}$and $\mathrm{CO}_{2}^{+}$ for resonance fluorescence excitation are nearly the same for a radial distance smaller than $500 \mathrm{~km}$ (see dash-dotted black curves in the top panels of Figure 15). This can be explained based on their g-factors and ion density distribution in the coma. It should be noticed that the g-factor of $\mathrm{CO}_{2}^{+}$is smaller by an order of magnitude compared to that of $\mathrm{CO}^{+}$(see the g-factor values for reactions E6 and E11 in Table B1), whereas its density is higher by more than an order of magnitude compared to that of $\mathrm{CO}^{+}$for the radial distances below $500 \mathrm{~km}$ (see Figure 14). In spite of the lower emission rate, the emission rate of $\mathrm{CO}_{2}^{+}$is comparable to that of $\mathrm{CO}^{+}$due its large density for these radial distances in the coma. Above a radial distance of $1000 \mathrm{~km}$ the density of $\mathrm{CO}^{+}$is higher than that of $\mathrm{CO}_{2}^{+}$which results in larger volume emission rate.

Assuming resonance fluorescence is the only primary excitation source, Opitom et al. (2019) converted the observed flux ratio $\left(\mathrm{I}_{\mathrm{CO}_{2}^{+}} / \mathrm{I}_{\mathrm{CO}}{ }^{+}\right)$into the ion density ratio $\left(\mathrm{CO}_{2}^{+} / \mathrm{CO}^{+}\right)$using the following expression.

$$
\frac{\left[\mathrm{CO}_{2}^{+}\right]}{\left[\mathrm{CO}^{+}\right]}=\frac{g_{\mathrm{CO}^{+}} I_{\mathrm{CO}_{2}^{+}}}{g_{\mathrm{CO}_{2}^{+}} I_{\mathrm{CO}^{+}}}
$$

Opitom et al. (2019) observed the average emission intensity ratio of $\mathrm{CO}_{2}^{+} / \mathrm{CO}^{+}$of about 0.15 , over the radial distance of $10^{4} \mathrm{~km}$, whereas the $\mathrm{g}$-factors ratio $\left(\mathrm{g}_{\mathrm{CO}}+/ \mathrm{g}_{\mathrm{CO}_{2}^{+}}\right)$is about 7. Hence, the product of $g$-factors ratio and the observed flux ratio results in the derived ion density as about 1 . When we account for $18 \% \mathrm{CO}_{2}$ with respect to $\mathrm{CO}$ production rate and resonance fluorescence as the only excitation mechanism for the $\mathrm{CO}_{2}^{+}$and $\mathrm{CO}^{+}$emissions, the modelled average emission intensity ratio over the projected distance of $5000 \mathrm{~km}$ is about 0.1 , which is consistent with the observed ion emission intensity ratio (see Figure 16). This agreement clearly suggests that the direct conversion of observed $\mathrm{CO}_{2}^{+} / \mathrm{CO}^{+}$ emission ratio into their corresponding neutral density ratio leads to a wrong estimation of $\mathrm{CO}_{2}$ abundance in the coma. The charge exchange between $\mathrm{CO}^{+}$and $\mathrm{CO}_{2}$ significantly affects both the $\mathrm{CO}^{+}$and $\mathrm{CO}_{2}^{+}$ion densities in the coma and consequently the observed $\mathrm{CO}_{2}^{+} / \mathrm{CO}^{+}$emission ratio. Hence, the ion-neutral chemistry in this CO-dominated coma plays an important role in modifying the ion composition in the coma and explain the discrepancy between observed $\mathrm{CO}_{2}$ abundance by McKay et al. (2019) and Opitom et al. (2019) derived $\mathrm{CO}_{2}^{+} / \mathrm{CO}^{+}$ion density ratios.

\subsubsection{Derivation of neutral density based on the $\mathrm{H}_{2} \mathrm{O}^{+} / \mathrm{CO}^{+}$emission intensity ratio}

Opitom et al. (2019) derived an upper limit for the $\mathrm{H}_{2} \mathrm{O}^{+} / \mathrm{CO}^{+}$density of about 0.4 by accounting for solar resonance fluorescence as the only excitation source of the corresponding ionic emissions. Since the g-factors ratio $\left(\mathrm{g}_{\mathrm{H}_{2} \mathrm{O}^{+}} / \mathrm{g}_{\mathrm{CO}}{ }^{+}\right)$of these ionic emissions is close to one, the observed upper limit of the emission intensity ratio should also be about 0.4 . Our modelled emission intensity ratio of these ions is smaller by more than two orders of magnitude compared to the derived upper limit of the observation (see
Figure 16). Moreover, our calculations in Figure 3 show that the formation and destruction of $\mathrm{H}_{2} \mathrm{O}^{+}$are majorly determined by the $\mathrm{CO}_{2}^{+}$and $\mathrm{CO}$ distribution in the coma, respectively, for radial distances below $1000 \mathrm{~km}$ rather than photoionization of $\mathrm{H}_{2} \mathrm{O}$. Even at large radial distances the contribution from charge exchange reactions is significant in determining the $\mathrm{H}_{2} \mathrm{O}^{+}$density. As discussed before, no significant change is observed in the modelled $\mathrm{H}_{2} \mathrm{O}^{+} / \mathrm{CO}^{+}$emission intensity profiles by accounting for only ionization and excitation mechanism or only solar resonance fluorescence excitation. This suggests that the these excitation processes equally contribute in determining the emission intensity ratio. Since this ion density is majorly controlled by charge transfer reactions rather than photon and electron impact initiated reactions, we suggest that the observed emission intensity ratio is not suitable to constrain the density of $\mathrm{H}_{2} \mathrm{O}$ in the cometary coma.

\section{SUMMARY AND CONCLUSIONS}

In the context of recent observations of the CO-dominated and water poor comet C/2016 R2, we developed a physicochemical model to study the ion density distribution and the emission processes of excitation states of various ions. We have studied various formation and destruction mechanisms of different ions by incorporating the ionization of neutrals by photons and photoelectrons, charge exchange reactions, proton transfer reactions, and electron-ion thermal recombination reactions. Besides the fluorescence excitation mechanism, ionization and excitation of corresponding neutral species, which produce excited states of $\mathrm{CO}^{+}, \mathrm{H}_{2} \mathrm{O}^{+}$, $\mathrm{N}_{2}^{+}$, and $\mathrm{CO}_{2}^{+}$, are also incorporated to study the emission mechanisms of these ions. The major results of the present work can be summarized as follows.

1. $\mathrm{CO}_{2}^{+}$is the major ion in this $\mathrm{CO}$-dominated coma for the radial distances smaller than $10^{3} \mathrm{~km}$. Above this distance $\mathrm{CO}^{+}$is the most abundant one.

2. The production of $\mathrm{CO}_{2}^{+}$is mainly controlled by charge transfer between $\mathrm{CO}^{+}$and $\mathrm{CO}_{2}$ for radial distances below $1000 \mathrm{~km}$ and above this distance, photoionization of $\mathrm{CO}_{2}$ is the major source of $\mathrm{CO}_{2}^{+}$.

3. Photoionization of $\mathrm{CO}$ is the primary source of $\mathrm{CO}^{+}$. The collisions with $\mathrm{CO}_{2}$ removes this ion for radial distances smaller than $1000 \mathrm{~km}$. Above this distance, thermal recombination is the significant loss source of $\mathrm{CO}^{+}$.

4. The charge transfer reactions of $\mathrm{CO}^{+}, \mathrm{CO}_{2}^{+}$and $\mathrm{O}^{+}$with $\mathrm{H}_{2} \mathrm{O}$ majorly determine the $\mathrm{H}_{2} \mathrm{O}^{+}$ion density in the inner coma rather than photoionization of $\mathrm{H}_{2} \mathrm{O}$. Collisions with $\mathrm{CO}$ remove $\mathrm{H}_{2} \mathrm{O}^{+}$for radial distances up to $5000 \mathrm{~km}$, and above this distance thermal recombination is the major loss processes.

5. Photoionization of $\mathrm{N}_{2}$ is the primary source of $\mathrm{N}_{2}^{+}$, whereas the loss of this ion is mainly due to collisions with $\mathrm{CO}_{2}$ and $\mathrm{CO}$ for radial distances up to $3000 \mathrm{~km}$, above which thermal recombination takes over as primary loss source.

6. The densities of protonated ions $\mathrm{H}_{3} \mathrm{O}^{+}, \mathrm{NH}_{4}^{+}$, and $\mathrm{CH}_{3} \mathrm{OH}_{2}^{+}$are majorly linked with the $\mathrm{H}_{2} \mathrm{O}$ distribution in the inner coma and the formation chemistry of these ions is determined by $\mathrm{CO}$ and $\mathrm{CO}_{2}$.

7. Resonance fluorescence is the most significant excitation mechanism for $\mathrm{N}_{2}^{+}$and $\mathrm{CO}^{+}$emissions, hence the observed 
$\mathrm{N}_{2}^{+} / \mathrm{CO}^{+}$ion emission intensity ratio can be used to derive their respective neutral density ratio in the cometary coma. 8. Since $\mathrm{CO}_{2}^{+}$and $\mathrm{H}_{2} \mathrm{O}^{+}$ion densities in the inner coma are significantly controlled by ion-neutral chemistry, rather than photoionization of neutrals, the observed $\mathrm{CO}_{2}^{+} / \mathrm{CO}^{+}$and $\mathrm{H}_{2} \mathrm{O}^{+} / \mathrm{CO}^{+}$emission intensity ratios can not be used to derive their respective neutral densities.

9. If the ion densities in the coma are determined by ionization of corresponding neutrals and thermal recombination, then the observed ion-emission intensity ratios can be converted into neutral density ratios. But if the ion density in the coma is essentially determined by ion-neutral chemistry, then the conversion leads to a wrong estimation of neutral abundances in the coma

10. Our modelled emission intensity ratio profiles $\mathrm{N}_{2}^{+} / \mathrm{CO}^{+}$, $\mathrm{H}_{2} \mathrm{O}^{+} / \mathrm{CO}^{+}$, and $\mathrm{CO}_{2}^{+} / \mathrm{CO}^{+}$are consistent with the recent ground based observations.

\section{ACKNOWLEDGEMENTS}

SR is supported by Department of Science and Technology (DST) with Innovation in Science Pursuit for Inspired Research (INSPIRE) faculty award [Grant: DST/INSPIRE/04/2016/002687], and he would like to thank Physical Research Laboratory for facilitating conducive research environment. DH and EJ are FNRS Senior Research Associates. The authors would like to thank the anonymous reviewer for the valuable comments and suggestions that improved the manuscript.

\section{DATA AVAILABILITY}

Based on observations made with ESO Telescopes at the La Silla Paranal Observatory under program 2100.C-5035(A). The modelled data can be available on the reasonable request to the corresponding author.

\section{REFERENCES}

Adams N. G., Smith D., Grief D., 1978, International Journal of Mass Spectrometry and Ion Processes, 26, 405

Adams N. G., Smith D., Paulson J. F., 1980, J. Chem. Phys., 72, 288

Allen M., Delitsky M., Huntress W., Yung Y., Ip W. H., 1987, A\&A, 187, 502

Altwegg K., et al., 1993, A\&A, 279, 260

Anicich V. G., 1993, ApJS, 84, 215

Anicich V. G., Futrell Wesley T. Huntress Jean H. J., 1976, Chemical Physics Letters, 40, 233

Anicich V. G., Kim J. K., Huntress W. T. J., 1977, International Journal of Mass Spectrometry and Ion Processes, 25, 433

Arpigny C., 1964, Annales d'Astrophysique, 27, 406

Arqueros F., Campos J., 1982, Physica B+C, 112, 131

Avakyan S. V., II'in R. N., Lavrov V. M., Ogurtsov G. N., eds, 1998, Collision Processes and Excitation of UV Emission from Planetary Atmospheric Gases: A Handbook of Cross Sections. Gordon and Breach Science Publishers

Balsiger H., et al., 1986, Nature, 321, 330

Beth A., Galand M., Heritier K. L., 2019, A\&A, 630, A47

Bhardwaj A., 1999, J. Geophys. Res., 104, 1929

Bhardwaj A., Raghuram S., 2012, Astrophys. J., 748, 13

Bhardwaj A., Haider S. A., Singhal R. P., 1990, Icarus, 85, 216

Bhardwaj A., Haider S. A., Singhal R. P., 1996, Icarus, 120, 412

Bieler A., et al., 2015, Nauture, 526, 678

Biver N., et al., 2018, Astron. \& Astrophys, 619, A127
Bockelée-Morvan D., Crovisier J., Mumma M. J., Weaver H. A., 2004, The composition of cometary volatiles: Comets II. University of Arizona Press, pp 391-423

Bowers M. T., Kemper P. R., Laudenslager J. B., 1974, J. Chem. Phys., 61, 4394

Brian J., Mitchell A., 1990, Phys. Rep., 186, 215

Cochran A. L., Cochran W. D., 1991, Icarus, 90, 172

Cochran A. L., McKay A. J., 2018, Astrophy. J. Lett., 854, L10

Cochran A. L., Cochran W. D., Barker E. S., 2000, Icarus, 146, 583

Combi M. R., Delsemme A. H., 1980, ApJ, 238, 381

Copp N. W., Hamdan M., Jones J. D. C., Birkinshaw K., Twiddy N. D., 1982, Chemical Physics Letters, 88, 508

Cordiner M. A., Charnley S. B., 2014, Meteoritics and Planetary Science, 49, 21

Cravens T., 1989, Advances in Space Research, 9, 293

Decock A., Jehin E., Rousselot P., Hutsemékers D., Manfroid J., Raghuram S., Bhardwaj A., Hubert B., 2015, Astron. \& Astrophys., 573, A1

Delsemme A. H., Combi M. R., 1979, Astrophys. J., 228, 330

Disanti M. A., Fink U., Schultz A. B., 1990, Icarus, 86, 152

Eberhardt P., Krankowsky D., 1995, Astronomy and Astrophysics, 295, 795

Fahey D. W., Fehsenfeld F. C., Ferguson E. E., 1981, Geophys. Res. Lett., 8, 1115

Feldman P. D., Cochran A. L., Combi M. R., 2004, Spectroscopic investigations of fragment species in the coma: Comets II. M. C. Festou, H. A. Weaver, \& H. U. Keller (Ed.)(Tucson: Univ. of Arizona), pp 425-447

Ferguson E. E., 1973, Atomic Data and Nuclear Data Tables, 12, 159

Fuselier S. A., et al., 2015, A\&A, 583, A2

Fuselier S. A., et al., 2016, MNRAS, 462, S67

Galand M., et al., 2016, Mon. Not. R. Astron. Soc., 462, S331

Gan L., Cravens T. E., 1990, J. Geophys. Res., 95, 6285

Geoghegan M., Adams N. G., Smith D., 1991, Journal of Physics B Atomic Molecular Physics, 24, 2589

Geppert W. D., et al., 2006, Faraday Discussions, 133, 177

Häberli R. M., Altwegg K., Balsiger H., Geiss J., 1995, A\&A, 297, 881

Häberli R. M., Combi M. R., Gombosi T. I., De Zeeuw D. L., Powell K. G., 1997, Icarus, 130, 373

Haider S. A., Bhardwaj A., 1997, Adv. Space Res., 20, 291

Haider S. A., Bhardwaj A., 2005, Icarus, 177, 196

Haider S. A., Bhardwaj A., Singhal R. P., 1993, Icarus, 101, 234

Hamberg M., et al., 2007, Molecular Physics, 105, 899

Haser L., 1957, Bull. Acad. R Sci Liege, 43, 740

Heritier K. L., et al., 2017, Mon. Not. R. Astron. Soc., 469, S427

Heritier K., et al., 2018, Nature Communications, 9, 2580

Huebner W. F., Keady J. J., Lyon S. P., 1992, Astrophys. Space Sci., 195,1

Huntress W. T. J., Pinizzotto R. F. J., 1973, J. Chem. Phys., 59, 4742

Huntress W. T. J., McEwan M. J., Karpas Z., Anicich V. G., 1980, ApJS, 44, 481

Ip W.-H., 1983, Astrophys. J., 264, 726

Ip W.-H., 2004, Global solar wind interaction and ionospheric dynamics: Comets II. M. C. Festou, H. A. Weaver, \& H. U. Keller (Ed.)(Tucson: Univ. of Arizona), pp 605-629

Ip W. H., et al., 1990, Annales Geophysicae, 8, 319

Itikawa Y., 2002, J. Phys. Chem. Ref. Data, 31, 749

Itikawa Y., 2009, Journal of Physical and Chemical Reference Data, 38,1

Itikawa Y., Mason N., 2005, J. Phys. Chem. Ref. Data, 34, 1

Jain D. C., Sahni R. C., 1966, J. Quant. Spectrosc. Radiative Transfer, 6, 705

Jones J. D. C., Birkinshaw K., Twiddy N. D., 1981, Chemical Physics Letters, 77, 484 
Judge D. L., Lee L. C., 1973, Journal of Physics B Atomic Molecular Physics, 6, 2150

Karpas Z., Anicich V. G., Huntress W. T. J., 1978, Chemical Physics Letters, 59, 84

Kim S. J., 1999, Earth Planets Space, 51, 139

Korsun P. P., Ivanova O. V., Afanasiev V. L., 2008, Icarus, 198, 465

Korsun P. P., Rousselot P., Kulyk I. V., Afanasiev V. L., Ivanova O. V., 2014, Icarus, 232, 88

Krankowsky D., et al., 1986, Nature, 321, 326

Krishna Swamy K. S., 1979, ApJ, 227, 1082

Larson S. M., 1980, ApJ, 238, L47

Liu W., Victor G. A., 1994, Astrophys Journal, 435, 909

Lofthus A., Krupenie P. H., 1977, Journal of Physical and Chemical Reference Data, 6, 113

Lutz B. L., 1987, ApJ, 315, L147

Lutz B. L., Womack M., Wagner R. M., 1993, ApJ, 407, 402

Magnani L., A'Hearn M. F., 1986, ApJ, 302, 477

McCallum J. C., Nicholls R. W., 1971, Journal of Physics B Atomic Molecular Physics, 4, 1096

McElroy D., Walsh C., Markwick A. J., Cordiner M. A., Smith K., Millar T. J., 2013, A\&A, 550, A36

McKay A., et al., 2019, arXiv e-prints, p. arXiv:1907.07208

Mitchell J. B. A., 1990, Phys. Rept., 186, 215

Mitchell D. L., et al., 1987, Science, 237, 626

Novotný O., et al., 2010, Journal of Physical Chemistry A, 114, 4870

Öjekull J., et al., 2004, J. Chem. Phys., 120, 7391

Opitom C., et al., 2019, Astron. \& Astrophys., 624, A64

Petuchowski S. J., Dwek E., Allen J. E. J., Nuth J. A. I., 1989, ApJ, 342, 406

Raghuram S., Bhardwaj A., 2013, Icarus, 223, 91

Raghuram S., Bhardwaj A., 2014, Astron. Astrophys., 566, A134

Raghuram S., Bhardwaj A., 2020, Icarus, 347, 113790

Raghuram S., Bhardwaj A., Galand M., 2016, Astrophys. J., 818, 102

Raghuram S., Hutsemékers D., Opitom C., Jehin E., Bhardwaj A., Manfroid J., 2020, A\&A, 635, A108

Rakshit A. B., Warneck P., 1980, Zeitschrift Naturforschung Teil A, 35,358

Rao M. V. V. S., Srivastava S. K., 1992, Journal of Physics B Atomic Molecular Physics, 25, 2175

Rosén S., et al., 1998, Phys. Rev. A, 57, 4462

Rosén S., et al., 2000, Faraday Discuss., 407, 295

Rowe B. R., Dupeyrat G., Marquette J. B., Smith D., Adams N. G., Ferguson E. E., 1984, J. Chem. Phys., 80, 241

Rubin M., Hansen K. C., Gombosi T. I., Combi M. R., Altwegg K., Balsiger H., 2009, Icarus, 199, 505

Rubin M., et al., 2015, Science, 348, 232

Schiff H. I., Bohme D. K., 1979, ApJ, 232, 740

Schmidt H. U., Wegmann R., Huebner W. F., Boice D. C., 1988, Comp. Phy. Comm., 49, 17

Sheehan C. H., St.-Maurice J. P., 2004, Journal of Geophysical Research (Space Physics), 109, A03302

Shirai T., Tabata T., Tawara H., 2001, Atomic Data and Nuclear Data Tables, 79, 143

Smith D., Adams N. G., 1977, International Journal of Mass Spectrometry and Ion Processes, 23, 123

Smith A. M., Stecher T. P., Casswell L., 1980, Astrophys. J., 242, 402

Srivastava S. K., Krishnakumar E., Fucaloro A. F., van Note T., 1996, J. Geophys. Res., 101, 26155

Straub H. C., Lin D., Lindsay B. G., Smith K. A., Stebbings R. F., 1997, J. Chem. Phys., 106, 4430

Swamy K. S. K., 1986, Earth Moon and Planets, 34, 281

Tabata T., Shirai T., M. S., Kubo H., 2006, Atomic Data and Nuclear Data Tables, 92, 375
Venkataramani K., Ganesh S., Baliyan K. S., 2020, arXiv e-prints, p. arXiv:2004.10266

Vigren E., Galand M., 2013, The Astrophysical Journal, 772, 33

Vigren E., et al., 2017, MNRAS, 469, S142

Wegmann R., Schmidt H. U., Huebner W. F., Boice D. C., 1987, A\&A, 187, 339

Wegmann R., Jockers K., Bonev T., 1999, Planet. Space Sci., 47, 745

Wierzchos K., Womack M., 2018, Astron. J., 156, 34

Wyckoff S., Heyd R. S., 2003, in AAS/Division for Planetary Sciences Meeting Abstracts \#35. p. 967

Wyckoff S., Theobald J., 1989, Advances in Space Research, 9, 157 
Table A1. The production and loss reactions of various ions considered in the chemical network

\begin{tabular}{|c|c|c|c|c|c|}
\hline \multirow{2}{*}{$\begin{array}{l}\text { Number } \\
\text { R1 }\end{array}$} & \multicolumn{3}{|c|}{ Reaction } & \multirow{2}{*}{$\frac{\text { Rate }\left(\mathrm{s}^{-1} \text { or } \mathrm{cm}^{3} \mathrm{~s}^{-1}\right)}{7.20 \times 10^{-7}}$} & \multirow{2}{*}{$\begin{array}{l}\text { Reference } \\
\text { This work }\end{array}$} \\
\hline & $\mathrm{h} \nu+\mathrm{CO}$ & $\rightarrow$ & $\mathrm{CO}^{+}+\mathrm{e}$ & & \\
\hline $\mathrm{R} 2$ & $\mathrm{~h} \nu+\mathrm{CO}_{2}$ & $\rightarrow$ & $\mathrm{CO}^{+}+\mathrm{e}$ & $9.48 \times 10^{-8}$ & This work \\
\hline R3 & $\mathrm{h} \nu+\mathrm{CO}_{2}$ & $\rightarrow$ & $\mathrm{CO}_{2}^{+}+\mathrm{e}$ & $1.25 \times 10^{-6}$ & This work \\
\hline $\mathrm{R} 4$ & $\mathrm{~h} \nu+\mathrm{H}_{2} \mathrm{O}$ & $\rightarrow$ & $\mathrm{H}_{2} \mathrm{O}^{+}+\mathrm{e}$ & $6.46 \times 10^{-7}$ & This work \\
\hline R5 & $\mathrm{h} \nu+\mathrm{N}_{2}$ & $\rightarrow$ & $\mathrm{N}_{2}^{+}+\mathrm{e}$ & $6.95 \times 10^{-7}$ & This work \\
\hline $\mathrm{R} 6$ & $\mathrm{~h} \nu+\mathrm{O}_{2}$ & $\rightarrow$ & $\mathrm{O}_{2}^{+}+\mathrm{e}$ & $9.10 \times 10^{-7}$ & This work \\
\hline $\mathrm{R} 7$ & $\mathrm{~h} \nu+\mathrm{CH}_{3} \mathrm{OH}$ & $\rightarrow$ & $\mathrm{CH}_{3} \mathrm{OH}^{+}+\mathrm{e}$ & $1.10 \times 10^{-6}$ & This work \\
\hline $\mathrm{R} 8$ & $\mathrm{~h} \nu+\mathrm{CH}_{4}$ & $\rightarrow$ & $\mathrm{CH}_{4}^{+}+\mathrm{e}$ & $7.20 \times 10^{-7}$ & This work \\
\hline $\mathrm{R} 9$ & $\mathrm{~h} \nu+\mathrm{CO}$ & $\rightarrow$ & $\mathrm{O}^{+}+\mathrm{C}+\mathrm{e}$ & $4.42 \times 10^{-8}$ & This work \\
\hline $\mathrm{R} 10$ & $\mathrm{~h} \nu+\mathrm{CO}_{2}$ & $\rightarrow$ & $\mathrm{O}^{+}+\mathrm{CO}+\mathrm{e}$ & $1.18 \times 10^{-7}$ & This work \\
\hline $\mathrm{R} 11$ & $\mathrm{~h} \nu+\mathrm{H}_{2} \mathrm{O}$ & $\rightarrow$ & $\mathrm{O}^{+}+\mathrm{H}_{2}+\mathrm{e}$ & $1.14 \times 10^{-8}$ & This work \\
\hline $\mathrm{R} 12$ & $\mathrm{~h} \nu+\mathrm{O}_{2}$ & $\rightarrow$ & $\mathrm{O}^{+}+\mathrm{O}+\mathrm{e}$ & $2.01 \times 10^{-7}$ & This work \\
\hline $\mathrm{R} 13$ & $\mathrm{~h} \nu+\mathrm{CO}$ & $\rightarrow$ & $\mathrm{C}^{+}+\mathrm{O}+\mathrm{e}$ & $5.45 \times 10^{-8}$ & This work \\
\hline $\mathrm{R} 14$ & $\mathrm{~h} \nu+\mathrm{CO}_{2}$ & $\rightarrow$ & $\mathrm{C}^{+}+\mathrm{O}_{2}+\mathrm{e}$ & $5.42 \times 10^{-8}$ & This work \\
\hline $\mathrm{R} 15$ & $\mathrm{e}_{p h}+\mathrm{CO}$ & $\rightarrow$ & $\mathrm{CO}^{+}+2 \mathrm{e}$ & Calculated & This work \\
\hline $\mathrm{R} 16$ & $\mathrm{e}_{p h}+\mathrm{CO}_{2}$ & $\rightarrow$ & $\mathrm{CO}_{2}^{+}+2 \mathrm{e}$ & Calculated & This work \\
\hline $\mathrm{R} 17$ & $\mathrm{e}_{p h}+\mathrm{H}_{2} \mathrm{O}$ & $\rightarrow$ & $\mathrm{H}_{2} \mathrm{O}^{+}+2 \mathrm{e}$ & Calculated & This work \\
\hline $\mathrm{R} 18$ & $\mathrm{e}_{p h}+\mathrm{N}_{2}$ & $\rightarrow$ & $\mathrm{N}_{2}^{+}+2 \mathrm{e}$ & Calculated & This work \\
\hline $\mathrm{R} 19$ & $\mathrm{e}_{p h}+\mathrm{O}_{2}$ & $\rightarrow$ & $\mathrm{O}_{2}^{+}+2 \mathrm{e}$ & Calculated & This work \\
\hline $\mathrm{R} 20$ & $\mathrm{e}_{p h}+\mathrm{CH}_{3} \mathrm{OH}$ & $\rightarrow$ & $\mathrm{CH}_{3} \mathrm{OH}^{+}+2 \mathrm{e}$ & Calculated & This work \\
\hline $\mathrm{R} 21$ & $\mathrm{e}_{p h}+\mathrm{CH}_{4}$ & $\rightarrow$ & $\mathrm{CH}_{4}^{+}+2 \mathrm{e}$ & Calculated & This work \\
\hline $\mathrm{R} 22$ & $\mathrm{e}_{p h}+\mathrm{CO}$ & $\rightarrow$ & $\mathrm{O}^{+}+\mathrm{C}+2 \mathrm{e}$ & Calculated & This work \\
\hline $\mathrm{R} 23$ & $\mathrm{e}_{p h}+\mathrm{CO}_{2}$ & $\rightarrow$ & $\mathrm{O}^{+}+\mathrm{CO}+2 \mathrm{e}$ & Calculated & This work \\
\hline $\mathrm{R} 24$ & $\mathrm{e}_{p h}+\mathrm{H}_{2} \mathrm{O}$ & $\rightarrow$ & $\mathrm{O}^{+}+\mathrm{H}_{2}+2 \mathrm{e}$ & Calculated & This work \\
\hline $\mathrm{R} 25$ & $\mathrm{e}_{p h}+\mathrm{O}_{2}$ & $\rightarrow$ & $\mathrm{O}^{+}+\mathrm{O}+2 \mathrm{e}$ & Calculated & This work \\
\hline $\mathrm{R} 26$ & $\mathrm{e}_{p h}+\mathrm{CO}$ & $\rightarrow$ & $\mathrm{C}^{+}+\mathrm{O}+2 \mathrm{e}$ & Calculated & This work \\
\hline $\mathrm{R} 27$ & $\mathrm{e}_{p h}+\mathrm{CO}_{2}$ & $\rightarrow$ & $\mathrm{C}^{+}+\mathrm{O}_{2}+2 \mathrm{e}$ & Calculated & This work \\
\hline $\mathrm{R} 28$ & $\mathrm{H}_{2} \mathrm{O}^{+}+\mathrm{H}_{2} \mathrm{O}$ & $\rightarrow$ & $\mathrm{H}_{3} \mathrm{O}^{+}+\mathrm{OH}$ & $2.10 \times 10^{-9} \mathrm{~T}_{n}$ & Huntress \& Pinizzotto (1973) \\
\hline $\mathrm{R} 29$ & $\mathrm{H}_{2} \mathrm{O}^{+}+\mathrm{CH}_{4}$ & $\rightarrow$ & $\mathrm{H}_{3} \mathrm{O}^{+}+\mathrm{CH}_{3}$ & $1.1 \times 10^{-9} \mathrm{~T}_{n}$ & Huntress et al. (1980) \\
\hline R30 & $\mathrm{H}_{2} \mathrm{O}^{+}+\mathrm{CO}$ & $\rightarrow$ & $\mathrm{HCO}^{+}+\mathrm{OH}$ & $5.0 \times 10^{-10}$ & Jones et al. (1981) \\
\hline R31 & $\mathrm{H}_{2} \mathrm{O}^{+}+\mathrm{NH}_{3}$ & $\rightarrow$ & $\mathrm{NH}_{4}^{+}+\mathrm{OH}$ & $9.45 \times 10^{-10} \mathrm{~T}_{n}$ & Anicich (1993) \\
\hline R32 & $\mathrm{H}_{2} \mathrm{O}^{+}+\mathrm{NH}_{3}$ & $\rightarrow$ & $\mathrm{NH}_{3}^{+}+\mathrm{H}_{2} \mathrm{O}$ & $2.21 \times 10^{-9} \mathrm{~T}_{n}$ & Anicich (1993) \\
\hline R33 & $\mathrm{H}_{2} \mathrm{O}^{+}+\mathrm{O}_{2}$ & $\rightarrow$ & $\mathrm{O}_{2}^{+}+\mathrm{H}_{2} \mathrm{O}$ & $4.6 \times 10^{-10}$ & Rakshit \& Warneck (1980) \\
\hline R34 & $\mathrm{H}_{3} \mathrm{O}^{+}+\mathrm{NH}_{3}$ & $\rightarrow$ & $\mathrm{NH}_{4}^{+}+\mathrm{H}_{2} \mathrm{O}$ & $2.21 \times 10^{-9} \mathrm{~T}_{n}$ & Smith et al. (1980) \\
\hline R35 & $\mathrm{H}_{3} \mathrm{O}^{+}+\mathrm{CH}_{3} \mathrm{OH}$ & $\rightarrow$ & $\mathrm{CH}_{3} \mathrm{OH}_{2}^{+}+\mathrm{H}_{2} \mathrm{O}$ & $2.5 \times 10^{-9} \mathrm{~T}_{n}$ & Anicich (1993) \\
\hline R36 & $\mathrm{CO}^{+}+\mathrm{H}_{2} \mathrm{O}$ & $\rightarrow$ & $\mathrm{H}_{2} \mathrm{O}^{+}+\mathrm{CO}$ & $1.79 \times 10^{-9} \mathrm{~T}_{n}$ & Huntress et al. (1980) \\
\hline $\mathrm{R} 37$ & $\mathrm{CO}^{+}+\mathrm{H}_{2} \mathrm{O}$ & $\rightarrow$ & $\mathrm{HCO}^{+}+\mathrm{CO}$ & $8.84 \times 10^{-10} \mathrm{~T}_{n}$ & Huntress et al. (1980) \\
\hline R38 & $\mathrm{CO}^{+}+\mathrm{NH}_{3}$ & $\rightarrow$ & $\mathrm{NH}_{3}^{+}+\mathrm{CO}$ & $2.02 \times 10^{-9} \mathrm{~T}_{n}$ & Huntress et al. (1980) \\
\hline R39 & $\mathrm{CO}^{+}+\mathrm{CO}_{2}$ & $\rightarrow$ & $\mathrm{CO}_{2}^{+}+\mathrm{CO}$ & $1.00 \times 10^{-9}$ & Adams et al. (1978) \\
\hline $\mathrm{R} 40$ & $\mathrm{CO}^{+}+\mathrm{O}_{2}$ & $\rightarrow$ & $\mathrm{O}_{2}^{+2}+\mathrm{CO}$ & $2.00 \times 10^{-10}$ & Ferguson (1973) \\
\hline $\mathrm{R} 41$ & $\mathrm{CO}^{+}+\mathrm{CH}_{4}$ & $\rightarrow$ & $\mathrm{CH}_{4}^{+}+\mathrm{CO}$ & $7.93 \times 10^{-10}$ & Adams et al. (1978) \\
\hline $\mathrm{R} 42$ & $\mathrm{CO}^{+}+\mathrm{CH}_{4}$ & $\rightarrow$ & $\mathrm{CH}_{3}^{4} \mathrm{CO}^{+}+\mathrm{H}$ & $5.20 \times 10^{-11}$ & Adams et al. (1978) \\
\hline $\mathrm{R} 43$ & $\mathrm{CO}^{+}+\mathrm{CH}_{4}$ & $\rightarrow$ & $\mathrm{HCO}^{+}+\mathrm{CH}_{3}$ & $4.55 \times 10^{-10}$ & Adams et al. (1978) \\
\hline $\mathrm{R} 44$ & $\mathrm{CO}_{2}^{+}+\mathrm{H}_{2} \mathrm{O}$ & $\rightarrow$ & $\mathrm{H}_{2} \mathrm{O}^{+}+\mathrm{CO}_{2}$ & $2.04 \times 10^{-9} \mathrm{~T}_{n}$ & Karpas et al. (1978) \\
\hline $\mathrm{R} 45$ & $\mathrm{CO}_{2}^{+}+\mathrm{H}_{2} \mathrm{O}$ & $\rightarrow$ & $\mathrm{HCO}_{2}^{+}+\mathrm{OH}$ & $7.56 \times 10^{-10} \mathrm{~T}_{n}$ & Karpas et al. (1978) \\
\hline $\mathrm{R} 46$ & $\mathrm{CO}_{2}^{+}+\mathrm{NH}_{3}$ & $\rightarrow$ & $\mathrm{NH}_{3}^{+}+\mathrm{CO}_{2}$ & $1.90 \times 10^{-9} \mathrm{~T}_{n}$ & Copp et al. (1982) \\
\hline $\mathrm{R} 47$ & $\mathrm{CO}_{2}^{+}+\mathrm{O}_{2}$ & $\rightarrow$ & $\mathrm{O}_{2}^{+}+\mathrm{CO}_{2}$ & $5.3 \times 10^{-11}$ & Copp et al. (1982) \\
\hline $\mathrm{R} 48$ & $\mathrm{CO}_{2}^{+}+\mathrm{CH}_{4}$ & $\rightarrow$ & $\mathrm{CH}_{4}^{+}+\mathrm{CO}_{2}$ & $5.5 \times 10^{-10}$ & Copp et al. (1982) \\
\hline
\end{tabular}


Table A1 - continued table

\begin{tabular}{|c|c|c|c|c|c|}
\hline Number & & act & & $\operatorname{Rate}\left(\mathrm{s}^{-1}\right.$ or $\left.\mathrm{cm}^{3} \mathrm{~s}^{-1}\right)$ & Reference \\
\hline $\mathrm{R} 49$ & $\mathrm{~N}_{2}^{+}+\mathrm{O}_{2}$ & $\rightarrow$ & $\mathrm{O}_{2}^{+}+\mathrm{N}_{2}$ & $3.5 \times 10^{-10}$ & Anicich (1993) \\
\hline R50 & $\mathrm{N}_{2}^{+}+\mathrm{CO}_{2}$ & $\rightarrow$ & $\mathrm{CO}_{2}^{+}+\mathrm{N}_{2}$ & $7.7 \times 10^{-10}$ & Adams et al. (1980) \\
\hline R51 & $\mathrm{N}_{2}^{+}+\mathrm{CH}_{4}$ & $\rightarrow$ & $\mathrm{CH}_{3}^{+}+\mathrm{N}_{2}+\mathrm{H}$ & $9.3 \times 10^{-10}$ & Adams et al. (1980) \\
\hline $\mathrm{R} 52$ & $\mathrm{~N}_{2}^{+}+\mathrm{CH}_{4}$ & $\rightarrow$ & $\mathrm{CH}_{2}^{+}+\mathrm{N}_{2}+\mathrm{H}_{2}$ & $7.0 \times 10^{-11}$ & Adams et al. (1980) \\
\hline $\mathrm{R} 53$ & $\mathrm{~N}_{2}^{+}+\mathrm{H}_{2} \mathrm{O}$ & $\rightarrow$ & $\mathrm{H}_{2} \mathrm{O}^{+}+\mathrm{N}_{2}$ & $2.8 \times 10^{-9}$ & Ferguson (1973) \\
\hline $\mathrm{R} 54$ & $\mathrm{~N}_{2}^{+}+\mathrm{H}_{2} \mathrm{O}$ & $\rightarrow$ & $\mathrm{N}_{2} \mathrm{H}^{+}+\mathrm{OH}$ & $2.12 \times 10^{-9}$ & Ferguson (1973) \\
\hline R55 & $\mathrm{N}_{2}^{+}+\mathrm{CO}$ & $\rightarrow$ & $\mathrm{CO}^{+}+\mathrm{N}_{2}$ & $7.40 \times 10^{-11}$ & Adams et al. (1980) \\
\hline $\mathrm{R} 56$ & $\mathrm{~N}_{2}^{+}+\mathrm{N}_{2}$ & $\rightarrow$ & $\mathrm{N}_{3}^{+}+\mathrm{N}$ & $5.5 \times 10^{-11}$ & Bowers et al. (1974) \\
\hline $\mathrm{R} 57$ & $\mathrm{~N}_{2}^{+}+\mathrm{NH}_{3}$ & $\rightarrow$ & $\mathrm{NH}_{3}^{+}+\mathrm{N}_{2}$ & $1.9 \times 10^{-9} \mathrm{~T}_{n}$ & Adams et al. (1980) \\
\hline $\mathrm{R} 58$ & $\mathrm{O}_{2}^{+}+\mathrm{NH}_{3}$ & $\rightarrow$ & $\mathrm{NH}_{3}^{+}+\mathrm{O}_{2}$ & $2.0 \times 10^{-9} \mathrm{~T}_{n}$ & Adams et al. (1980) \\
\hline R59 & $\mathrm{O}_{2}^{+}+\mathrm{CH}_{4}$ & $\rightarrow$ & $\mathrm{HCOOH}_{2}^{+}+\mathrm{H}$ & $3.2 \times 10^{-10}$ & Rowe et al. (1984) \\
\hline R60 & $\mathrm{O}_{2}^{+}+\mathrm{CH}_{3} \mathrm{OH}$ & $\rightarrow$ & $\mathrm{CH}_{3} \mathrm{OH}^{+}+\mathrm{O}_{2}$ & $5.0 \times 10^{-10} \mathrm{~T}_{n}$ & Adams et al. (1978) \\
\hline $\mathrm{R} 61$ & $\mathrm{CH}_{4}^{+}+\mathrm{O}_{2}$ & $\rightarrow$ & $\mathrm{O}_{2}^{+}+\mathrm{CH}_{4}$ & $3.9 \times 10^{-10}$ & Anicich (1993) \\
\hline $\mathrm{R} 62$ & $\mathrm{CH}_{4}^{+}+\mathrm{CO}_{2}$ & $\rightarrow$ & $\mathrm{HCO}_{2}^{+}+\mathrm{CH}_{3}$ & $1.2 \times 10^{-9}$ & Smith \& Adams (1977) \\
\hline $\mathrm{R} 63$ & $\mathrm{CH}_{4}^{+}+\mathrm{CO}$ & $\rightarrow$ & $\mathrm{HCO}^{+}+\mathrm{CH}_{3}$ & $1.4 \times 10^{-9}$ & Smith \& Adams (1977) \\
\hline R64 & $\mathrm{CH}_{4}^{+}+\mathrm{H}_{2} \mathrm{O}$ & $\rightarrow$ & $\mathrm{H}_{3} \mathrm{O}^{+}+\mathrm{CH}_{3}$ & $2.6 \times 10^{-9} \mathrm{~T}_{n}$ & Smith \& Adams (1977) \\
\hline $\mathrm{R} 65$ & $\mathrm{CH}_{4}^{+}+\mathrm{NH}_{3}$ & $\rightarrow$ & $\mathrm{NH}_{4}^{+}+\mathrm{CH}_{3}$ & $1.15 \times 10^{-9} \mathrm{~T}_{n}$ & Smith \& Adams (1977) \\
\hline $\mathrm{R} 66$ & $\mathrm{CH}_{4}^{+}+\mathrm{CH}_{3} \mathrm{OH}$ & $\rightarrow$ & $\mathrm{CH}_{3} \mathrm{OH}_{2}^{+}+\mathrm{CH}_{3}$ & $1.20 \times 10^{-9} \mathrm{~T}_{n}$ & Adams et al. (1978) \\
\hline R67 & $\mathrm{CH}_{4}^{+}+\mathrm{CH}_{3} \mathrm{OH}$ & $\rightarrow$ & $\mathrm{CH}_{3} \mathrm{OH}^{+}+\mathrm{CH}_{4}$ & $1.80 \times 10^{-9} \mathrm{~T}_{n}$ & Adams et al. (1978) \\
\hline R68 & $\mathrm{CH}_{4}^{+}+\mathrm{CH}_{4}$ & $\rightarrow$ & $\mathrm{CH}_{5}^{+}+\mathrm{CH}_{3}$ & $1.5 \times 10^{-9}$ & Smith \& Adams (1977) \\
\hline R69 & $\mathrm{CH}_{3}^{4} \mathrm{OH}^{+}+\mathrm{H}_{2} \mathrm{O}$ & $\rightarrow$ & $\mathrm{H}_{2} \mathrm{O}^{+}+\mathrm{CH}_{3} \mathrm{OH}$ & $1.5 \times 10^{-9}$ & Haider \& Bhardwaj (2005) \\
\hline R70 & $\mathrm{NH}_{3}^{+}+\mathrm{H}_{2} \mathrm{O}$ & $\rightarrow$ & $\mathrm{NH}_{4}^{+}+\mathrm{OH}$ & $1.1 \times 10^{-10}$ & Anicich et al. (1977) \\
\hline R71 & $\mathrm{NH}_{3}^{+}+\mathrm{NH}_{3}$ & $\rightarrow$ & $\mathrm{NH}_{4}^{+}+\mathrm{N}$ & $2.2 \times 10^{-9} \mathrm{~T}_{n}$ & Adams et al. (1980) \\
\hline $\mathrm{R} 72$ & $\mathrm{NH}_{3}^{+}+\mathrm{CO}$ & $\rightarrow$ & $\mathrm{CO}^{+}+\mathrm{NH}_{3}$ & $1.1 \times 10^{-9} \mathrm{~T}_{n}$ & Adams et al. (1980) \\
\hline R73 & $\mathrm{CH}_{3} \mathrm{OH}_{2}^{+}+\mathrm{NH}_{3}$ & $\rightarrow$ & $\mathrm{NH}_{4}^{+}+\mathrm{CH}_{3} \mathrm{OH}$ & $1.1 \times 10^{-9} \mathrm{~T}_{n}$ & McElroy et al. (2013) \\
\hline R74 & $\mathrm{C}^{+}+\mathrm{CH}_{4}$ & $\rightarrow$ & $\mathrm{C}_{2} \stackrel{\mathrm{H}}{2}_{2}^{+}+\mathrm{H}_{2}$ & $3.89 \times 10^{-10}$ & Schiff \& Bohme (1979) \\
\hline R75 & $\mathrm{C}^{+}+\mathrm{CH}_{4}$ & $\rightarrow$ & $\mathrm{C}_{2} \mathrm{H}_{3}^{+}+\mathrm{H}$ & $1.00 \times 10^{-9}$ & Schiff \& Bohme (1979) \\
\hline R76 & $\mathrm{C}^{+}+\mathrm{CO}_{2}$ & $\rightarrow$ & $\mathrm{CO}^{+}+\mathrm{CO}$ & $1.10 \times 10^{-9}$ & Fahey et al. (1981) \\
\hline $\mathrm{R} 77$ & $\mathrm{C}^{+}+\mathrm{H}_{2} \mathrm{O}$ & $\rightarrow$ & $\mathrm{HOC}^{+}+\mathrm{H}$ & $2.09 \times 10^{-9}$ & Anicich \& Futrell (1976) \\
\hline $\mathrm{R} 78$ & $\mathrm{C}^{+}+\mathrm{H}_{2} \mathrm{O}$ & $\rightarrow$ & $\mathrm{HCO}^{+}+\mathrm{H}$ & $9.00 \times 10^{-10}$ & Anicich \& Futrell (1976) \\
\hline $\mathrm{R} 79$ & $\mathrm{C}^{+}+\mathrm{NH}_{3}$ & $\rightarrow$ & $\mathrm{H}_{2} \mathrm{NC}^{+}+\mathrm{H}$ & $1.61 \times 10^{-9}$ & Smith \& Adams (1977) \\
\hline $\mathrm{R} 80$ & $\mathrm{C}^{+}+\mathrm{NH}_{3}$ & $\rightarrow$ & $\mathrm{NH}_{3}^{+}+\mathrm{C}$ & $6.72 \times 10^{-10}$ & Smith \& Adams (1977) \\
\hline $\mathrm{R} 81$ & $\mathrm{C}^{+}+\mathrm{O}_{2}$ & $\rightarrow$ & $\mathrm{CO}^{+}+\mathrm{O}$ & $3.40 \times 10^{-10}$ & Smith \& Adams (1977) \\
\hline $\mathrm{R} 82$ & $\mathrm{C}^{+}+\mathrm{O}_{2}$ & $\rightarrow$ & $\mathrm{O}^{+}+\mathrm{CO}$ & $4.50 \times 10^{-10}$ & Smith \& Adams (1977) \\
\hline $\mathrm{R} 83$ & $\mathrm{O}^{+}+\mathrm{CO}$ & $\rightarrow$ & $\mathrm{CO}^{+}+\mathrm{O}$ & $4.90 \times 10^{-12} \mathrm{~T}_{n}$ & Petuchowski et al. (1989) \\
\hline $\mathrm{R} 84$ & $\mathrm{O}^{+}+\mathrm{H}_{2} \mathrm{O}$ & $\rightarrow$ & $\mathrm{H}_{2} \mathrm{O}^{+}+\mathrm{O}$ & $3.20 \times 10^{-9} \mathrm{~T}_{n}$ & Adams et al. (1980) \\
\hline $\mathrm{R} 85$ & $\mathrm{O}^{+}+\mathrm{NH}_{3}$ & $\rightarrow$ & $\mathrm{NH}_{3}^{+}+\mathrm{O}$ & $1.20 \times 10^{-9} \mathrm{~T}_{n}$ & Adams et al. (1980) \\
\hline $\mathrm{R} 86$ & $\mathrm{O}^{+}+\mathrm{O}_{2}$ & $\rightarrow$ & $\mathrm{O}_{2}^{+}+\mathrm{O}$ & $1.90 \times 10^{-11}$ & Adams et al. (1980) \\
\hline $\mathrm{R} 87$ & $\mathrm{O}^{+}+\mathrm{CH}_{4} \mathrm{OH}$ & $\rightarrow$ & $\mathrm{H}_{3} \mathrm{CO}^{+}+\mathrm{OH}$ & $1.33 \times 10^{-9} \mathrm{~T}_{n}$ & Adams et al. (1980) \\
\hline $\mathrm{R} 88$ & $\mathrm{O}^{+}+\mathrm{CH}_{4}$ & $\rightarrow$ & $\mathrm{CH}_{3}^{+}+\mathrm{OH}$ & $1.10 \times 10^{-10}$ & Adams et al. (1980) \\
\hline R89 & $\mathrm{O}^{+}+\mathrm{CO}_{2}$ & $\rightarrow$ & $\mathrm{O}_{2}^{+}+\mathrm{CO}$ & $9.40 \times 10^{-10}$ & Adams et al. (1980) \\
\hline R90 & $\mathrm{O}^{+}+\mathrm{N}_{2}$ & $\rightarrow$ & $\mathrm{NO}^{+}+\mathrm{N}$ & $2.40 \times 10^{-12} \mathrm{~T}_{n}$ & Adams et al. (1980) \\
\hline R91 & $\mathrm{O}^{+}+\mathrm{CH}_{4} \mathrm{OH}$ & $\rightarrow$ & $\mathrm{CH}_{3} \mathrm{OH}^{+}+\mathrm{O}$ & $4.75 \times 10^{-10} \mathrm{~T}_{n}$ & Adams et al. (1980) \\
\hline
\end{tabular}

Photoionization rates presented in this table are calculated at 1 au heliocentric distance; $\mathrm{T}_{n}=(300 / \mathrm{T})^{0.5}$; $\mathrm{h} \nu$ and $\mathrm{e}_{p h}$ are solar photon and photoelectron, respectively. 
Table A2. Thermal recombination reactions of various ions considered in the chemical network.

\begin{tabular}{llllll}
\hline \hline Number & \multicolumn{2}{c}{ Reaction } & Rate $\left(\mathrm{cm}^{3} \mathrm{~s}^{-1}\right)$ & Reference \\
\hline $\mathrm{L} 1$ & $\mathrm{H}_{3} \mathrm{O}^{+}+\mathrm{e}_{t h}$ & $\rightarrow$ & Products & $4.30 \times 10^{-7} \times(300 / \mathrm{T})^{0.83}$ & Novotný et al. (2010) \\
$\mathrm{L} 2$ & $\mathrm{H}_{2} \mathrm{O}^{+}+\mathrm{e}_{t h}$ & $\rightarrow$ & Products & $4.30 \times 10^{-7} \times(300 / \mathrm{T})^{0.50}$ & Rosén et al. (2000) \\
$\mathrm{L} 3$ & $\mathrm{CO}_{2}^{+}+\mathrm{e}_{t h}$ & $\rightarrow$ & Products & $3.50 \times 10^{-7} \times(300 / \mathrm{T})^{0.50}$ & Geoghegan et al. (1991) \\
$\mathrm{L} 4$ & $\mathrm{CO}^{+}+\mathrm{e}_{t h}$ & $\rightarrow$ & Products & $2.75 \times 10^{-7} \times(300 / \mathrm{T})^{0.50}$ & Rosén et al. (1998) \\
$\mathrm{L} 5$ & $\mathrm{~N}_{2}^{+}+\mathrm{e}_{t h}$ & $\rightarrow$ & Products & $2.20 \times 10^{-7} \times(300 / \mathrm{T})^{0.39}$ & Sheehan \& St.-Maurice (2004) \\
$\mathrm{L} 6$ & $\mathrm{O}_{2}^{+}+\mathrm{e}_{t h}$ & $\rightarrow$ & Products & $1.95 \times 10^{-7} \times(300 / \mathrm{T})^{0.70}$ & Sheehan \& St.-Maurice (2004) \\
$\mathrm{L} 7$ & $\mathrm{NH}_{4}^{+}+\mathrm{e}_{t h}$ & $\rightarrow$ & Products & $9.34 \times 10^{-7} \times(300 / \mathrm{T})^{0.60}$ & Öjekull et al. (2004) \\
$\mathrm{L} 8$ & $\mathrm{NH}_{3}^{+}+\mathrm{e}_{t h}$ & $\rightarrow$ & Products & $3.10 \times 10^{-7} \times(300 / \mathrm{T})^{0.60}$ & Brian \& Mitchell (1990) \\
$\mathrm{L} 9$ & $\mathrm{CH}_{3} \mathrm{OH}^{+}+\mathrm{e}_{t h}$ & $\rightarrow$ & Products & $1.80 \times 10^{-6} \times(300 / \mathrm{T})^{0.66}$ & Hamberg et al. (2007) \\
$\mathrm{L} 10$ & $\mathrm{CH}_{3} \mathrm{OH}_{2}^{+}+\mathrm{e}_{t h}$ & $\rightarrow$ & Products & $8.36 \times 10^{-7} \times(300 / \mathrm{T})^{0.66}$ & Geppert et al. (2006) \\
$\mathrm{L} 11$ & $\mathrm{CH}_{4}^{+}+\mathrm{e}_{t h}$ & $\rightarrow$ & Products & $3.50 \times 10^{-7} \times(300 / \mathrm{T})^{0.50}$ & Mitchell (1990) \\
\hline
\end{tabular}

$\mathrm{e}_{t h}$ and $\mathrm{T}$ are thermal electron and electron temperature, respectively.

Table B1. Reactions for the formation of different excited states of ions via photoionization, electron impact ionization of neutrals and resonance fluorescence excitation of ion.

\begin{tabular}{|c|c|c|c|c|c|}
\hline \multirow{2}{*}{$\begin{array}{l}\text { Number } \\
\text { E1 }\end{array}$} & \multicolumn{3}{|c|}{ Reaction } & \multirow{2}{*}{$\begin{array}{l}\begin{array}{l}\text { Frequency } \\
\left(\mathrm{s}^{-1} \text { or photons } \mathrm{s}^{-1} \text { molecule }^{-1}\right)\end{array} \\
1.04 \times 10^{-7}\end{array}$} & \multirow{2}{*}{$\begin{array}{l}\text { Reference } \\
\text { This work }\end{array}$} \\
\hline & $\mathrm{h} \nu+\mathrm{H}_{2} \mathrm{O}$ & $\rightarrow$ & $\mathrm{H}_{2} \mathrm{O}^{+}\left(\underset{\sim}{\widetilde{A}^{2}} \mathrm{~A}_{1}\right)+\mathrm{e}_{p h}$ & & \\
\hline $\mathrm{E} 2$ & $\mathrm{e}_{p h}+\mathrm{H}_{2} \mathrm{O}$ & $\rightarrow$ & $\mathrm{H}_{2} \mathrm{O}^{+}\left(\underset{\widetilde{A}^{2}}{\mathrm{~A}_{1}}\right)+2 \mathrm{e}$ & Calculated & This work \\
\hline E3 & $\mathrm{h} \nu+\mathrm{H}_{2} \mathrm{O}^{+}$ & $\rightarrow$ & $\mathrm{H}_{2} \mathrm{O}^{+}\left(\widetilde{A}^{2} \mathrm{~A}_{1}\right)$ & $4.2 \times 10^{-3}$ & Lutz et al. (1993) \\
\hline $\mathrm{E} 4$ & $\mathrm{~h} \nu+\mathrm{CO}_{2}$ & $\rightarrow$ & $\mathrm{CO}_{2}^{+}\left(\widetilde{\sim}^{2} \Pi_{u}\right)+\mathrm{e}_{p h}$ & $2.50 \times 10^{-7}$ & This work \\
\hline E5 & $\mathrm{e}_{p h}+\mathrm{CO}_{2}$ & $\rightarrow$ & $\mathrm{CO}_{2}^{+}\left(\widetilde{A}^{2} \Pi_{u}\right)+2 \mathrm{e}$ & Calculated & This work \\
\hline E6 & $\mathrm{h} \nu+\mathrm{CO}_{2}^{+}$ & $\rightarrow$ & $\mathrm{CO}_{2}^{+}\left(\widetilde{A}^{2} \Pi_{u}\right)$ & $4.96 \times 10^{-4}$ & Kim (1999) \\
\hline E7 & $\mathrm{h} \nu+\mathrm{CO}_{2}$ & $\rightarrow$ & $\mathrm{CO}^{+}\left(\mathrm{A}^{2} \Pi\right)+\mathrm{e}_{p h}$ & $9.05 \times 10^{-8}$ & This work \\
\hline $\mathrm{E} 8$ & $\mathrm{~h} \nu+\mathrm{CO}$ & $\rightarrow$ & $\mathrm{CO}^{+}\left(\mathrm{A}^{2} \Pi\right)+\mathrm{e}_{p h}$ & $2.44 \times 10^{-7}$ & This work \\
\hline E9 & $\mathrm{e}_{p h}+\mathrm{CO}_{2}$ & $\rightarrow$ & $\mathrm{CO}^{+}\left(\mathrm{A}^{2} \Pi\right)+2 \mathrm{e}$ & Calculated & This work \\
\hline E10 & $\mathrm{e}_{p h}+\mathrm{CO}$ & $\rightarrow$ & $\mathrm{CO}^{+}\left(\mathrm{A}^{2} \Pi\right)+2 \mathrm{e}$ & Calculated & This work \\
\hline E11 & $\mathrm{h} \nu+\mathrm{CO}^{+}$ & $\rightarrow$ & $\mathrm{CO}^{+}\left(\mathrm{A}^{2} \Pi\right)$ & $3.55 \times 10^{-3}$ & Magnani \& A'Hearn (1986) \\
\hline E12 & $\mathrm{h} \nu+\mathrm{N}_{2}$ & $\rightarrow$ & $\mathrm{N}_{2}^{+}\left(\mathrm{B}^{2} \Sigma_{u}^{+}\right)+\mathrm{e}_{p h}$ & $5.48 \times 10^{-8}$ & This work \\
\hline E13 & $\mathrm{e}_{p h}+\mathrm{N}_{2}$ & $\rightarrow$ & $\mathrm{N}_{2}^{+}\left(\mathrm{B}^{2} \Sigma_{u}^{+}\right)+2 \mathrm{e}$ & Calculated & This work \\
\hline E14 & $\mathrm{h} \nu+\mathrm{N}_{2}^{+}$ & $\rightarrow$ & $\mathrm{N}_{2}^{+}\left(\mathrm{B}^{2} \Sigma_{u}^{+}\right)$ & $7 \times 10^{-2}$ & Lutz et al. (1993) \\
\hline
\end{tabular}

$\mathrm{h} \nu, \mathrm{e}_{p h}$, and e are solar photon and photoelectron, and electron, respectively. The photoionization frequencies and g-factors presented in this table are at 1 au heliocentric distance. 
APPENDIX C: DERIVATION OF $\mathrm{N}_{2} / \mathrm{CO}$

DENSITY RATIO BASED ON THE OBSERVED ION EMISSION RATIO

$$
\begin{aligned}
\frac{I_{N_{2}^{+}}}{I_{C O^{+}}} & =\frac{g_{N_{2}^{+}}}{g_{C O^{+}}} \frac{\left[N_{2}^{+}\right]}{\left[C O^{+}\right]} \\
& =\frac{g_{N_{2}^{+}}}{g_{C O^{+}}} \frac{\left[N_{2}\right] q_{n_{2}^{+}}}{n_{e} R_{n_{2}^{+}}} \frac{n_{e} R_{c O^{+}}}{[C O] q_{c o^{+}}} \\
& =\frac{g_{N_{2}^{+}}}{g_{C O^{+}}} \frac{\left[N_{2}\right]}{[C O]} \frac{q_{n_{2}^{+}}}{q_{c o^{+}}} \frac{R_{c o^{+}}}{R_{n_{2}^{+}}}
\end{aligned}
$$

$\frac{\left[N_{2}\right]}{[C O]}=\frac{I_{N_{2}^{+}}}{I_{C O^{+}}} \frac{g_{C O}+q_{c o^{+}} R_{n_{2}^{+}}}{g_{N_{2}^{+}} q_{n_{2}^{+}} R_{c o^{+}}}$

here $q_{c o}$ and $q_{n_{2}^{+}}$are the photoionization frequencies of $\mathrm{CO}$ and $\mathrm{N}_{2}$ producing $\mathrm{CO}^{+}$and $\mathrm{N}_{2}^{+}$ions, respectively (see the calculated values for reactions R1 and R5 in Appendix Table A1). $R_{c o^{+}}$and $R_{n_{2}^{+}}$are recombination rates of $\mathrm{CO}^{+}$ and $\mathrm{N}_{2}^{+}$ions, respectively (see reaction rates L4 and L5 in Appendix Table A2). $n_{e}$ is total electron density. Substituting the constant values in equation $\mathrm{C} 2$, we get

$\frac{\left[N_{2}\right]}{[C O]}=\frac{I_{N_{2}^{+}}}{I_{C O^{+}}} \times 1.69 \times 10^{-2} \times T_{e}^{0.16}$

here $T_{e}$ is electron temperature. 
This paper has been typeset from a $\mathrm{T}_{\mathrm{E}} \mathrm{X} / \mathrm{LAT}_{\mathrm{E}} \mathrm{X}$ file prepared by the author. 